\title{
5. Die Prozessakten: Formen der Justiz und koloniale Subjektgenerierung
}

Dieses Kapitel behandelt zwei zeitlich und personell eng miteinander verflochtene Prozesse und deren Akten: erstens der Juicio de Residencia (Amtsprüfverfahren) zur Amtsführung der Welser und zweitens der pleito criminal (Kriminalprozess) gegen Juan de Carvajal. Trotz ihrer engen personellen und zeitlichen Verbindungen verfolgen die beiden Prozesse als Formen des Justizvollzugs völlig unterschiedliche Zielsetzungen. Während die Form des Juicio de Residencia einen gewöhnlichen Bestandteil im Verlauf einer Amtsperiode jedes Magistrats darstellt, wird ein Kriminalprozess aufgrund eines außergewöhnlichen Ereignisses initiiert; während eine Residencia alle möglichen Berichte über Handlungen der Amtsträger sammelt und bilanziert, nimmt ein Kriminalprozess ein als außergewöhnlich taxiertes Ereignis zum Anlass eines Prozesses. Typischerweise wird in einem solchen Fall das Ereignis erst im Nachhinein durch das Instrument des Kriminalprozesses zur kriminellenTat erklärt (vgl. Weisser 1979: 3).

Richter beider Prozesse war Juan Pérez de Tolosa, der bereits im Jahr 1545 zum Untersuchungsrichter (Juez de Residencia) der Provinz Venezuela ernannt worden war. Im Auftrag der Krone reiste er also im Jahr darauf nach Coro, um die Amtsführung der Welser-Gouverneure zu bilanzieren. Im Zuge seiner Erkundungen wurde er schon bald aufmerksam auf die Enthauptungen, Ereignisse, die ihn zur ungeplanten Aufnahme eines Kriminalprozesses veranlassten.

Das vorliegende Kapitel ist in einem ersten Teil theoretisch ausgerichtet, indem es mögliche Funktionen der Prozesse, ihrer Figuren und Mittel hinsichtlich der Kolonialisierung, der Interpellation und der Mechanismen kolonialer Subjektgenerierung betrachtet und reflektiert. Darauf aufbauend werden anschließend die konkreten Akten der beiden Prozesse analysiert. 
Die Justiz wurde im vorliegenden Zusammenhang in zweifacher Hinsicht und in zwei verschiedenen Prozessformen wirksam: einerseits hinsichtlich der im Jahr 1546 anstehenden Überprüfung der Welser-Statthalterschaft, andererseits, um die >Wahrheit< über die blutigen Ereignisse um die Auseinandersetzung Hutten-Carvajal herauszufinden. Im Folgenden werden zunächst beide Prozessformen, ihre wichtigsten zugeordneten Figuren inklusive deren Instrumente und schließlich die Textform »Akte« erläutert.

\section{Die Prozessformen Juicio de Residencia und pleito criminal}

Juicios de Residencia (oder auch kurz Residencias genannt) dienten dazu, die Amtsführung aller Beamten des Reiches - sowohl im Mutterland Spanien wie in Übersee - am Ende ihrer Amtszeit einer Untersuchung zu unterziehen. Die in den Residencias zur Anwendung gebrachte Fragebogentechnik, mit der alle Bewohner der Provinz (im vorliegenden Fall zur Amtsführung der Welser) befragt wurden, geht auf die mittelalterliche inquisitio zurück. Deren Sinn und Zweck zwischen dem 8. und dem 15. Jahrhundert war es

erstens, in einem bestimmten Moment (meist einem casus necessitatis) ein Inventar der Güter und Einkünfte eines Herren vorzulegen; zweitens, die Art seiner Rechte, die Bedingungen ihrer Ausübung, aber auch ihre Crenzen festzulegen; drittens, zu erreichen, daß diese Daten rechtswirksame Form annahmen und irgendwann vorgezeigt werden konnten (Siegert 2003a: 541).

Ähnlich wie diese Inquisitionsverfahren hatten die Residencias zum Ziel, in einem bestimmten Moment innezuhalten und über die Amtsführung der Funktionäre Bilanz zu ziehen. So wie die Inquisitionsverfahren »von bevollmächtigten Kommissaren ausgeübt wurde[n], die speziell für die Durchführung von Datenerhebungen ernannt wurden« (ebd.: 540), bestimmte der König zur Durchführung der Residencias jeweils einen Juez de Residencia, der während dieser Zeit vor Ort residierte (daher die Bezeichnung Residencia, vgl. Mariluz Urquijo 1952: 3). Diesem oblagen während der gesamten Zeit der Residencia alle Regierungsgeschäfte. Alle Funktionäre mussten ihre Amtsstäbe dem Richter buchstäblich abgeben. Die Übergabe der Stäbe fand in einer Zeremonie statt, ${ }^{1}$ die den Juez de Residencia für eine bestimmte Zeit zum Richter und Regenten in Personalunion machte.

Die Zentralmacht verschaffte sich auf diese Weise eine allumfassende Präsenz unter den Bedingungen der Absenz, des Entferntseins vom Geschehen, das zu steuern war (vgl. Herzog 2004: 108). Die Produktion der Akten indes stellte einen Strang jener diskursiven Verbindung zwischen Zentrum und Pe- 
ripherie her, die Rama »Nabelschnur« (vgl. 1998: 46) genannt hatte und in dieser Studie unter dem Begriff »bürokratischer Apparat « gefasst wurde. Wie die Interpellation in der konkreten Ausformung als Juicio de Residencia zum Tragen kommt, soll im Folgenden ausgelotet werden. Eine zentrale Rolle spielt dabei der festgelegte Ablauf des Verfahrens, der eine bestimmte Form von Akten hervorbrachte, in denen sich die kolonialen Subjekte auf eine ganz bestimmte Weise textuell konstituierten.

Zum zweiten hier diskutierten Prozess - dem pleito criminal (Kriminalprozess) - kam es, als Juan Pérez de Tolosa im Zuge erster Erkundungen während der Residencia kurz nach seiner Ankunft von den Enthauptungen Philipps von Hutten, Bartholomäus Welsers, Diego Romeros und Gregorio de Plasencias gehört hatte und in der Folge eine Untersuchung gegen den von allen Seiten beschuldigten Juan de Carvajal einleitete. Tolosa befragte mit Hilfe seiner escribanos (Schreiber oder Notare) einige Zeugen, die nach den von Carvajal angeordneten Enthauptungen aus seinem Sitz in El Tocuyo geflohen und etwa zeitgleich mit dem Richter in Coro angekommen waren. Tolosa organisierte daraufhin einen Tross zur Verhaftung Carvajals, nachdem er ihn in öffentlicher Versammlung - also noch bevor >Beweise vorlagen - der Tat für schuldig befunden hatte. Carvajal befand sich zu jenem Zeitpunkt noch immer in El Tocuyo, wo ihn Tolosa im August 1546 nach der Durchführung des ersten Teils des Kriminalprozesses verhaftete.

Dieser Kriminalprozess macht die Tendenz sichtbar, die im Verlauf des 16. Jahrhunderts das Strafrecht zu einem Teil staatlicher Autorität werden ließ (vgl. Weisser 1979: 99f.). Es ging nicht mehr länger darum, einen Streit unter zwei privaten Parteien zu schlichten und zu lösen. Indem der Staat das Monopol auf die Strafverfolgung übernahm, bekam er ein Machtmittel an die Hand, die Gesellschaft als Ganze in solche bis dahin privat zu regelnden Zwistigkeiten einzubeziehen. "With the appearance of the state as the sole source of prosecutional energy, the criminal act could no longer be viewed as an attack by one person to another; it was now an offence committed against society at large.« (Ebd.: 100) Auf diese Weise erfolgte über den bürokratischen Apparat - in diesem Fall hergestellt durch den Prozess und seine Akten - die Interpellation der Bewohnerinnen und Bewohner eines Ortes, an dem sich die kriminelle Tat ereignet hatte. Wenn sich ein krimineller Akt gegen die Gesellschaft richtete, hatte diese auch Interesse daran, die schuldige Partei zu bestrafen. Das Ziel der Strafverfolgung war es nicht mehr in erster Linie, die geschädigte Partei zu entschädigen. Die Bestrafung an sich wurde 
zum Selbstzweck. Eine Folge davon war »a general increase in the severity of punishments« (ebd.).

Es wird aber auch noch etwas anderes sichtbar. Gemäß Weisser definiere die Gesellschaft »in an ex post facto fashion what activities constitute criminal behaviour, and the nature of crime as it is formally defined often has little connection with its original function or cause. Indeed the legal description of an criminal act often bears little resemblance to the actual criminal event." (Ebd.: 4) Die ursprüngliche Tat - hier die Enthauptung Huttens und seiner drei Gefährten durch Carvajal - wird in den Akten des Prozesses als kriminelle Handlung abgeurteilt, den Carvajal aus purem bösem Willen begangen haben soll. Sein Geständnis am Schluss des Prozesses, dass er allein schuldig ist und böswillig gehandelt hat, liefert eine komplett andere Version der Geschichte, als er sie selber zu Beginn dargestellt hatte. Diese Wandlung ist Indiz dafür, dass der Prozess kein Mittel sein konnte, die >Wahrheit< über die tatsächliche Begebenheit herauszufinden: »Even the judicial procedure utilised to determine the extent of criminal activity becomes a charade, a ritualised set of motions that has no relationsship to the crime or the criminal« (ebd.).

\section{Der escribano als Träger der Interpellation}

Während sich in Huttens Briefen durch die Interpellation ein koloniales Subjekt konstituiert, muss im Falle der Akten von einem komplexen Subjektgefüge gesprochen werden. Dieses wird im Sinne Cornelia Vismanns, die Akten treffenderweise als "prozessgeneriert« (2011: 23) bezeichnet hat, durch das Zusammenwirken verschiedener Akteure, Abläufe und Mechanismen hervorgebracht. Der bürokratische Apparat offenbart sich in Fleisch und Blut, verkörpert durch die Auftritte und Handlungen der beiden Figuren Richter und escribano. Letzterer spielt in besonderer Weise eine schillernde Rolle im Gefüge der kolonialen lokalen Verhältnisse, wie im Folgenden gezeigt werden soll.

Nach Luján Muñoz (1977: 137) war der escribano Sekretär und Notar in einem; er hatte einerseits die Aufgabe, Schriften und Verträge zwischen Privatleuten $\mathrm{zu}$ autorisieren und andererseits die Gerichtsprozesse zu verschriftlichen. Luján Muñoz, der in seinem Buch die Rolle des escribano in »las Indias occidentales« untersucht, weist ihm eine zentrale Rolle in der in hohem Maße bürokratisch organisierten Verwaltung - dem bürokratischen Apparat - zu:

La organización administrativa indiana, altamente jerarquizada y burocrática, requirió un enorme aparato de funcionarios. El sistema centralista nece- 
sitó de una gran cantidad de oficiales secretariales. A todos los niveles había que cumplir engorrosos trámites de papeleo, y los escribanos fueron, en sus diversos niveles, los que cumplieron estas funciones. ${ }^{2}$ (Ebd.: 138)

Weiter stellt er fest, dass die escribanos das Funktionieren des komplizierten Systems der beschwerlichen Amtswege gewährleisteten, indem sie in turbulenten Zeiten, in denen Gouverneure kamen und gingen, durch ihre Tätigkeit Konstanz, Ordnung und Routine schufen. Mit ihren Unterschriften hätten sie der Krone das Einhalten der vorgeschriebenen Gesetzeswege und Verwaltungsvorgänge auch in weit entfernten Regionen garantiert. Verstärkend wirkte zudem der Umstand, dass das Amt des escribano käuflich erworben werden musste: Gemäß Mariluz Urquijo (1952: 76) achteten die escribanos peinlich genau darauf, dass kein Funktionär sein Amt beendete, ohne dem Juicio de Residencia unterzogen zu werden. Die escribanos waren auf Schreibaufträge angewiesen, weil sie ihren finanziellen Einsatz, den sie für den Zuspruch ihres Amtes aufzuwenden hattten, durch Gebühren für ihre Tätigkeit als Schreiber decken mussten. So verschafften sie der Krone zuverlässig eine Form von Präsenz vor Ort, die sie für die Erhaltung und Durchsetzung der Macht dringend benötigte.

Der Einfluss der escribanos ist in diesem Sinne aufgrund ihrer Stellung zwischen der Bevölkerung und den ihnen in der administrativen Hierarchie übergeordneten Funktionären nicht zu unterschätzen. Im Gegenteil: Ihre Tätigkeit als Schreiber war es, durch die »the colonial Latin American archive was formed« (Burns 2010: 3). Sie gehörten dem erweiterten Kreis der von Rama (vgl. 1998) sogenannten »ciudad letrada« an, die nach Burns weit weniger exklusiv war als gemeinhin angenommen. Als Angehörige dieser städtischen Konzentration von Gelehrten herrschten sie über die »offiziellen Kanäle und Instrumente der Kommunikation« (Burns 2010: 3). Luján Muñoz (1977: 138) schreibt ihnen große Macht $\mathrm{zu}$, die in einer weitgehenden Interpretationsfreiheit der Gesetze besteht. ${ }^{3}$ Beispielsweise konnte Schuld oder Unschuld des Angeklagten in hohem Maße vom escribano abhängen. In diesem Sinn hatte sich gemäß Burns der escribano González de Turneo geäußert: Er hatte beobachtet, dass die escribanos in den eröffnenden Runden von Kriminalprozessen die Zeugenaussagen nach Gutdünken notierten. Auch wenn Zeuginnen und Zeugen Beschuldigte entlasteten, würden die escribanos »only put [in writing] what makes him look guilty, when they should put down everything he says« (Burns 2010: 34). Gemäß Burns würden die Notare bei der >Übersetzung`der Zeugenaussagen in Schrift eine »shaped, collaborative truth« (ebd.) hervor- 
bringen. In einer Endnote macht die Autorin darauf aufmerksam, dass es zwar unmöglich sei, abzuschätzen, wie stark die Aussagen durch die Schreiber geformt oder poliert worden seien; auf jeden Fall sei aber davon auszugehen, dass das Urteil über die Schuld der Angeklagten maßgeblich zu deren Ungunsten beeinflusst werden konnte (vgl. ebd.: 168f.). ${ }^{4}$ In diesem Sinne stellt sie an späterer Stelle (vgl. ebd.: 147) die Frage, wessen Stimme eigentlich in den Aussagen der Zeugen >registriert worden sei, die vor den kolonialen $\mathrm{Au}$ toritäten geschworen hätten, die Wahrheit zu sagen. Die Frage sei schwer zu beantworten:

That depends on many things [...], including which stage of the case one is reading (sumaria o plenaria), the degree of notarial »purification « of the testimony, and the relations between interrogators and witnesses. It may be not possible to tell about all these things, especially when the records are incomplete. (Ebd.)

Um der Gefahr vereinfachender Generalisierungen bei der Lektüre von Prozessakten aus dem kolonialen Archiv wenigstens ein Stück weit zu begegnen, schlägt Burns vor, möglichst viel über die Prozesssituation herauszufinden, wie Kriminalfälle aufgenommen, weitergeführt, wie sie entschieden worden seien und wie Berufung eingelegt worden sei. Das Vorgehen nennt sie in Anlehnung an Rebecca Scott »making the documents speak« (ebd.); ${ }^{5}$ es soll auch bei der hier vorliegenden Analyse angewendet werden.

\section{Manuale und Formulare: Wahrheitsschablonen}

So groß der Einfluss des escribano auch war, er war nicht (nur) von persönlicher Macht getragen, sondern von seinem Amt, das ihm unter anderem den Einsatz bestimmter sprachlicher, notarieller Formeln erlaubte. Diese »standard, well-worn forms « (ebd.: 24) lenkten die delegierte Macht in die vom Imperium gewünschten Bahnen. Es handelte sich um Formeln und Textmodelle, mit denen die escribanos die Inhalte der Dokumente auswählten und formten: "Filtering and shaping the contents of documents was basically what notaries did for a living « (ebd.). Entsprechend ihrer in erster Linie praktischen und kaum theoretischen Ausbildung waren die escribanos auf Manuale angewiesen, auf die sie zurückgreifen konnten. Diese Manuale enthielten Muster und Textvorlagen für praktisch alle Fälle und Arten von Dokumenten, die ein Notar im Laufe seiner Amtsausübung erstellen musste (vgl. Luján Muñoz 1977: 142). Solche Manuale waren sehr gefragt, weil sie die einzige Quelle für die Informationen waren, die die Notare zur Erstellung der gefragten Dokumente 
benötigten. Ansonsten existierten keinerlei Standardisierung oder Normierung, an denen sie sich hätten orientieren können. ${ }^{6}$ Nach Reyes Rojas García (2012: \$11) wurden sie von escribanos erstellt, deren Wissen aus ihrer tagtäglichen Praxis stammte; aus diesem Grund, so die Autorin weiter, hätten die Manuale als "juristisch-praktische Führer« eine schnelle Verbreitung gefunden und seien »mit den lokalen Gebräuchen angereichert (ebd.) worden. Das heißt, dass die Textmodelle, die in den Manualen zur Verfügung gestellt wurden, bei Gebrauch jeweils an die lokalen aktuellen Gegebenheiten und an die konkrete Situation angepasst werden mussten.

Die Modelle waren als ganze Texteinheiten konzipiert, die neben angemessenen Formulierungen auch Inhalte oder gleich konkrete Plots mitlieferten. ${ }^{7}$ Die Figuren, die darin vorkamen, wurden jeweils mit »fulano « bezeichnet, als Platzhalter, an deren Stelle der Schreiber die Namen der aktuell beteiligten und zu bezeichnenden Personen einsetzen konnte. Nun stellt sich natürlich die Frage, wie weit solche bis in die inhaltlichen Details ausgearbeiteten Vorlagen in das Schreiben der jeweils neu zu erstellenden Dokumente einflossen. Welche Teile der Vorlagen konnte der Schreiber unverändert übernehmen? Welche musste er anpassen oder gar weglassen? Wenn wir die Akten eines Prozesses vor uns haben, liegen ihnen immer bis zu einem bestimmten Grad Muster zugrunde, die möglicherweise eher aus den erwähnten Vorlagen übernommen wurden, als dass sie aus den konkreten Umständen und den Begebenheiten der aktuellen Situation hervorgingen. »If we know what notaries were empowered to do, we can see that even the most seemingly spontaneous archival >voices often obey submerged but quite specific scripts. The archive becomes an echo chamber of blended, collaborative agencies.«(Burns 2010: 24) ${ }^{8}$ Die Vorlagen sorgten für eine Gleichförmigkeit der Dokumente, und dies über Jahrhunderte. Burns wundert sich darüber, dass Jahrhunderte von ungleichen und ausbeuterischen Beziehungen viele Millionen von swahren` Übereinkommen gleicher Machart hinterlassen hätten, und zwar unabhängig von Ort und Zeit der Entstehung:

Clearly this is truth by template - a truth reconizable not by its singularity, but by its very regularity. The overwhelming textual impression conveyed by notarial records is one of the unity of event and recordation: the tag phrases »before me (ante mí)《 and »which I certify« (de que doy fé) [sic!] recur throughout, as though the notary were drawing up documents himself at the very moment of agreement. But as we'll see, document production happened in stages, and might involve various writers and multiple scenes 
of writing. The unities are textual artifacts of this historical process. (Ebd.:

37)

Was es zu schaffen galt, waren möglichst gleichförmige, reguläre Texte. Trotzdem mussten natürlich die Spezifika der einzelnen Fälle, die in Prozessen verhandelt wurden, in die Akten eingehen. Wie das resultierende Verhältnis zwischen Prozess und Akten zu bestimmen ist, untersucht das folgende Unterkapitel.

\section{Akten}

Wenn Akten "prozessgeneriert« sind, wie Vismann (2011: 23) eine Vertreterin der Archivwissenschaft zitiert, heißt das, dass bei ihrer Produktion potentiell die ganze Palette von Mechanismen mitspielt. Diese Machart der Akten ruft ein dichtes Netz von Äußerungen hervor. In Kathryn Burns Worten: Akten sind kein transparentes »Fenster« (2010: 16), die uns direkten Zugang zu Stimmen aus der Vergangenheit verschaffen, denn:

spoken words did not pass unfiltered into the record. Notarial agency (perhaps undeclared and invisible) gave records their words and final form. We thus have to modify the imagined subjects of our archives to make room for a blended, composite agency includes the notary, even in the records that seem most spontaneous. For notaries [...] were the instruments of the early modern archive (ebd.: 39).

Die Praktiken initiieren einen Produktionsmechanismus, der ein ganzes Knäuel spezifischer kolonialer Subjekte hervorbringt, dessen einzelne Fäden und Stränge sich kaum entwirren lassen. Um die Akten in ihrem >Makingof $\mathrm{zu}$ begreifen, lesen wir mit Antennen, die in alle Richtungen weisen; Antennen, die empfänglich sind für die Wahrnehmung jeglicher Art von Regelmäßigkeiten und Unregelmäßigkeiten wie »material and textual patterns, small slippages, and sleights of hand « (Burns 2010: 125). Eine derartige Lesart mache klar, dass das Archiv eher einem Schachbrett denn einem Fenster gleiche (vgl. ebd.: 124). Das Bild suggeriert, dass der Blick durch das Fenster den Ausschnitt einer bestimmten Realität zeigt, wie sie ist; ein Schachbrett hingegen weist immer eine bestimmte Figurenkonstellation auf, die teilweise auf Intentionen und Taktiken der Spielenden zurückgehen, sich teilweise aber auch einfach durch die Zwänge der Spielregeln ergeben: Die >Figuren 
Möglichkeiten des Systems, ihren Intentionen und persönlichen Taktiken vor, woraus sich in der Folge bestimmte >Figurenkonstellationen ergeben.

Die Struktur der Akten sowohl des Juicio de Residencia als auch des Kriminalprozesses zeigt, dass in den Dokumenten keineswegs einfach der Gang der Prozesse aufgezeichnet wurde. Wäre dies der Fall, würden sie der Chronologie der Prozessschritte folgen und diese abbilden. Tatsächlich zeigen die beiden Akten eine nachträgliche Bearbeitung und Zusammenstellung der einzelnen Schreibprodukte, die während des Prozesses anfielen. Diese >Schlussredaktion geschah jeweils auf Anweisung des Richters, die ihrerseits explizit in den Akten festgehalten wurde. Daneben lassen sich aber weitere Eingriffe beobachten, die entweder auf mündlich erteilte, nicht dokumentierte Anweisungen erfolgten, oder aber auf Initiative der escribanos selbst vorgenommen wurden. So nahm beispielsweise der escribano der Akten des pleito criminal die erste öffentliche Rede des Richters Tolosa in Coro, in der dieser Carvajal explizit der Enthauptungen bezichtigte und eine Strafverfolgung verlangte, in die Akten auf, ohne dass Tolosa dies explizit angeordnet hätte. Oder, um ein anderes Beispiel zu nennen: Wie kommt es, dass ganze Passagen der Aussagen der beiden Zeugen Diego Ruiz de Vallejo und Cristóbal de Aguirre wortwörtlich übereinstimmen? Es ist kaum vorstellbar, dass die beiden Zeugen ihre Aussage im selben Wortlaut gemacht haben. Welche Umstände mögen wohl dazu geführt haben, dass der escribano denselben Text an zwei Stellen platziert hat?

Prozess und Akten sind zwei Größen, die zwar zusammenhängen, aber dennoch jeweils eigenen Bedingungen und Funktionsweisen unterworfen sind. Im Kriminalprozess kündigt der Anklagevertreter Deldua beispielsweise an, er werde alles Notwendige beweisen und über jedes einzelne der besagten Delikte reichlich Informationen durch »Schrift und Zeugen« (»escritura y testigos«, Morón 1977: 469) liefern. Dass er beide Medien gleichwertig nebeneinanderstellt, zeigt, dass die Schrift in den Dokumenten nicht bloß wiedergibt, was die Zeugen berichten, sondern dass beide Prozesse Zeugenbefragungen und das Verschriftlichen durch den Schreiber - ihre je eigenen Funktionen erfüllen. Der Diskursraum >Prozess < birgt spezielle Praktiken, die Akten als eine eigene Art Text hervorbringen, die ihre eigene Art von Lektüre einfordert. Akten sind mit Cornelia Vismann nicht das, was ihr Name suggeriert. Die Bedeutungsverschiebung "von mündlichen Handlungen $\mathrm{zu}$ schriftlichen Akten«, die der Begriff Akten durchmacht, weist auf die Entwicklung einer Verwaltung hin, »welche die Amtlichkeit ihrer 
Handlungen zunehmend an die schriftliche Erfassung derselben koppelt« (Vismann 2011: 79).

Im Folgenden werden die Dokumente der Residencia beschrieben. Es werden diejenigen Teile fokussiert, die inhaltlich mit dem Kriminalprozess gegen Carvajal zusammenhängen. Grundlage der Analyse sind die beiden Akten hauptsächlich in der Version der venezolanischen Transkription von 1977 (vgl. Morón 1977: 362-464, 465-544). ${ }^{9}$ Eine Zeugenaussage - nämlich diejenige von Diego Ruiz de Vallejo, des Verfassers des Briefes (siehe Kapitel 6) - wurde in der genannten Edition nicht transkribiert. Deshalb greift die Lektüre an jener Stelle auf das Manuskript zurück, das mir das AGI in Form eines Scans zur Verfügung gestellt hat. ${ }^{10}$

\section{Die Akten des Juicio de Residencia zur Amtsführung der Welser}

Das Transkriptionsteam Morón führt einleitend aus, dass das Hauptproblem der Forschung im Bereich der Juicios de Residencia der Provinz Venezuela neben der schieren Menge der Dokumente darin bestehe, dass die Quellen in den diversen Archiven verstreut lägen (vgl. Morón 1977: 15). Richter Juan Pérez de Tolosa habe dem Consejo de Indias ${ }^{11}$ die Abschriften des Juicio de Residencia zu den Welsern nicht in einem einzigen Aktenbündel, sondern, verteilt auf die Jahre 1547 und 1548, erst nach Abschluss des Kriminalprozesses gegen Carvajal in verstreuter Form nach Spanien geschickt (vgl. ebd.: 19). Heute liegen die gebündelten Akten des Prozesses der Residencia im Indienarchiv in Sevilla (AGI). ${ }^{12}$

Das Deckblatt (vgl. M: $\left.\mathrm{N}^{\mathrm{O}} 149,362\right)^{13}$ enthält die Informationen $\mathrm{zu}$ allen Eckpunkten, welche die Akten mit dem bürokratischen Apparat verbinden und sie damit in seinem Rahmen verankern: die Residencia, der König, der Indienrat, der Richter, der escribano und die Akten selbst.

Información hecha ante el Señor Licenciado Juan Pérez de Tolosa Juez de Residencia y Cobernador en esta provincia y gobernación de Venezuela por ante mí Ramos de Argañarás escribano de la dicha Residencia que va para ante Su Magestad y los señores su Presidente y Oidores de Su May Alto Consejo de Indias en que van setenta hojas y una plana en que va mi signo, escritas y tres hojas y media en blanco, la cual vá cerrada y sellada, Ramos de Argañarás. Rubricado ${ }^{14}$ (M: $\left.N^{0} 149,362\right)$. 
Die zentrale Rolle des escribano wird in und durch dieses Schreiben gleichzeitig dar- und hergestellt: die »información« (>Erkundung< und >Information`) wird zwar von dem vom König bestellten Juez de Residencia durchgeführt; wer aber wortwörtlich den Kontakt zum Papier und zum Archiv herstellt, ist der Schreiber, der sich auch gleich in der ersten Person in Szene setzt. Das von ihm in Tolosas Auftrag angefertigte und versiegelte Aktenbündel, das aus siebzig beschriebenen und dreieinhalb unbeschriebenen Seiten besteht - all das verkörpert als Ganzes das Zeichen der Interpellation und der Repräsentation der Macht. Siegel und rúbrica des escribano garantieren >Wahrheit<, die nach den Vorgaben des Imperiums generiert worden ist. »These inscriptions promised that he [the notary; SG] had been there, a superintending presence [...]. If he certified that something had taken place, then it became a legal fact, strue in law.« (Burns 2010: 75)

Tolosas Auftrag - die Provisión - muss in doppelter Weise verzeichnet und in Gang gesetzt werden: Erstens protokolliert der Schreiber die Übergabe des Schriftstückes (»entregaba y entregó a mí el dicho escribano la Provisión original«, $M: \mathrm{N}^{\circ} 151,363$ ) und zweitens transkribiert er seinen Wortlaut (vgl. »Real Provisión«, M: $\mathrm{N}^{\mathrm{O}} 151,363-366$, ausgestellt in Valladolid am 12. September 1545). Auch die Capitulación wird auf diese doppelte Weise in die Akten aufgenommen: Einerseits wird deren Übergabe protokolliert, andererseits wird ihr Inhalt vollständig transkribiert.

In der genannten Real Provisión wird der genaue Auftrag des Königs an Pérez de Tolosa formuliert. Das Schreiben wird mit einer akribisch geführten Liste aller von Karl V. beherrschten Reiche eröffnet. Die Macht des Souveräns wird damit nicht nur dargestellt, sondern jedes Mal von Neuem buchstäblich hergestellt, wenn man bedenkt, dass jeder Schreiber und jeder Leser sich zunächst durch diese Zeilen kämpfen muss:

Don Carlos, por la Divina clemencia Emperador siempre Augusto, Rey de Alemania, Doña Juana su madre, y el mismo Don Carlos por la misma gracia, Reyes de Castilla, de León, de Aragón, de las dos Sicilias, de Jerusalem, de Navarra, de Granada, de Toledo, de Valencia, de Galicia, de Mallorca, de Sevilla, de Cerdeña, de Córdoba, de Córcega, de Murcia, de Jaen, de Los Algarves, de Algeciras, de Gibraltar, de las Islas Canarias, de las Indias, islas y tierra firme del Mar Océano, Condes de Flandes y de Tirol etc. ${ }^{15}$ (M: $\left.\mathrm{N}^{0} 151,363\right)$

Die teils sehr großen Distanzen, die sich zwischen den beherrschten Ländern öffnen, müssen überwunden, die immer bestehende Gefahr des Machtverlusts des unter Umständen weit entfernten Hofes möglichst gebannt werden. 
Wie die Schrift für die Aufzählung der beherrschten Reiche Platz auf dem Papier der Urkunde beansprucht, erobert sie in ihrer Botschaft, legitimiert durch die Macht, den Raum.

Im nächsten Abschnitt wird der zum Juez de Residencia Ernannte namentlich angesprochen:

A vos el Licenciado Juan Pérez de Tolosa [...] es nuestra merced y voluntad de mandar tomar Residencia a los gobernadores que han sido y son de la provincia de Venezuela y Cabo de la Vela y a sus Alcaldes Mayores, Tenientes y Oficiales, del tiempo que han usado y ejercicio [ejercido?; SG] la nuestra justicia en ella y confiando de vos que sois tal persona, que entenderéis en ello, y en todo lo demás que por nos vos fuere mandado ${ }^{16}$ (ebd.).

Die persönliche Ansprache zielt direkt auf die Herstellung von verpflichtendem Vertrauen zwischen dem Souverän und seinem Untertan ab. Dem Juez de Residencia wird befohlen, sich in die besagte "provincia de Venezuela y Cabo de la Vela« zu begeben, dort die »baras de la nuestra Justicia y Residencia« (die `Stäbe der Justiz`) von den ansässigen Funktionären zu übernehmen und etwaige Klagen von der Bevölkerung innerhalb 90 Tagen gemäß den Gesetzen und Edikten aufzunehmen und richterlich zu beurteilen (vgl. ebd.: $\mathrm{N}^{\circ}$ 151, 364). Dazu müsse er sich informieren und geheime Erkundungen (»información secreta«) über das Verhalten und die Amtsführung der Funktionäre einholen. Wenn diese beschuldigt würden, solle er die Wahrheit herausfinden (»averigueis la verdad«), Recht sprechen und vollziehen sowie unverzüglich Bericht erstatten, damit der Hof über den Zustand in jener Provinz informiert sei. Er solle für zwei Jahre dort residieren, Regierung und Verwaltung der Provinz übernehmen und alle zivilen sowie strafrechtlichen Dinge und Fälle, die die Amtsträger abgewickelt hätten, erkunden und nachprüfen (»conozcais de todas las cosas y casos que en ella se ofrecieren así civiles como criminales $\aleph^{17}$ ). Ausnahmslos alle Amtsträger der Provinz würden suspendiert und müssten ihm ihre Amtsgeschäfte unverzüglich übergeben. Der Juez de Residencia müsse vorher feierlich einen Eid ablegen, wie es der Brauch fordere:

[S] uspendemos a los dichos gobernadores y a sus tenientes, Alcaldes Mayores y Oficiales, y mandamos a los Consejos, Justicias y Regidores, caballeros, escuderos, oficiales y hombres buenos de todas las ciudades, villas y lugares de la dicha provincia que luego que con esta nuestra carta fueren requeridos sin esperar para ello nuestra carta segunda ni tercera jusión, y sin poner en ello excusa ni dilación alguna reciban de vos el juramento y solemnidad que 
en tal caso se requiere y acostumbra hacer al cual por vos hechos os den y entreguen las dichas baras de la nuestra justicia para que vos las tengáis por el dicho tiempo de dos años ${ }^{18}\left(M: N^{0} 151,365\right)$.

Es fällt auf, dass alle erdenklichen Arten von Amtsträgern aufgezählt werden, anstatt, wie man nicht zuletzt wegen des notorischen Papiermangels erwarten würde, einen zusammenfassenden Oberbegriff zu verwenden oder überhaupt das Wissen um die Gestaltung eines Juicio de Residencia, der ja gängige Praxis war, vorauszusetzen. Interessant ist der Hinweis, dass die Stäbe unverzüglich, das heißt ohne einen zweiten oder dritten königlichen Brief abzuwarten und ohne >Ausreden (»excusas«) der Amtsmänner übergeben werden sollen. Er ist so konkret ausformuliert, dass vermutet werden kann, er beziehe sich auf Vorkommnisse früherer Jahre, als solle jedes erdenkliche Schlupfloch gestopft werden.

Die Residencias zielen also in erster Linie auf Missstände $a b$, genau wie die Visitations- beziehungsweise Inquisitionsinterrogationen nach "Anzeichen von Mißständen, die es zu beheben galt« (Siegert 2003a: 553), fragten. Und genau wie in diesen wird in den Residencias ein »empirisches Wissen« generiert, "das im Kontext der Visitationen ein negatives Wissen war (ein Wissen davon, wie die Welt von ihrem Sollzustand abweicht)« (ebd). Der Juez de Residencia des vorliegenden Falls, Juan Pérez de Tolosa, sollte, so die oben wiedergegebene »Real Provisión«, die >Wahrheit herausfinden« (»averiguar la

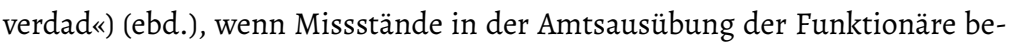
klagt würden. Doch welche Art >Wahrheit ist hier gemeint? In erster Linie geht es darum, die zusammengetragenen Daten rechtswirksam zu machen. Der Hof, die Öffentlichkeit, muss etwas als >wahr $<$ erkennen, damit es politisch wirksam werden kann (vgl. Siegert 2003b: 66). Das »empirische Wissen« dagegen, das die Welt beschreibt, wie sie ist, sollte als "positive[s] Wissen « erst 30 Jahre später zur Sprache kommen: Mittels der Fragebogentechnik wollte Juan de Ovando Daten erheben, die das Wissen sicherstellen sollten, das der Indienrat brauchte, um >las Indias` vor dem Untergang zu retten (Siegert 2003a: 544f.).

Dem Juez de Residencia wird viel Macht zugesprochen; er kann seinen Stellvertreter und seine Funktionäre nach Belieben ernennen und absetzen (»useis [la dicha jurisdicción] [...] por vos y por vuestro lugarteniente y oficiales que para ello podais poner y los quitar y admover durante el dicho tiempo [de dos años] cada que quisiéreis«, $N^{\circ}, 365$ ). Wenn Richter Ämter besetzen, sie den bedachten Funktionären aber jederzeit auch wieder entziehen konnten, 
mussten Abhängigkeiten entstehen. Eine umgekehrte Abhängigkeit wurde geschaffen, indem die Bezahlung des Richters indirekt über die lokalen Funktionäre abgewickelt wurde. Denn Letztere hatten unter Androhung von Strafe dem Richter jede Art von Hilfe zukommen zu lassen, damit er die Anweisungen des Königs ausführen könne. Eine etwaige Strafe konnte der Richter im Namen seiner Majestät aussprechen (»vos damos poder cumplido para las [i.e., las penas; SG] ejecutar a los rebeldes e inobedientes fueren «, $\mathrm{N}^{\circ}$ 151, 366). Damit wurde ein Netz von gegenseitigen Abhängigkeiten gesponnen. Kathryn Burns erinnert daran, dass Dokumente »were made in relationships« - Beziehungen, die von »unequal power« (2010: 126) geprägt gewesen sein mögen. Die Abhängigkeiten bestanden übereinstimmend in den beiden diskutierten Prozessen, denn sie wurden mehr oder weniger vom selben Personal geführt. Die beschriebenen Abhängigkeiten müssen bei der Lektüre stets mitbedacht werden.

Am Anfang der Residencia steht der pregón, das öffentliche Ausrufen ihres Beginns; alle Einwohner - auch diejenigen, die des Lesens nicht mächtig sind - sollen in den Prozess einbezogen werden. So wird der »Edicto« (M: $\mathrm{N}^{\mathrm{o}}$ 153, 366) am 16. Juni 1546 in Anwesenheit des größten Teils der Bewohner Coros vor der Kirche durch den »Pregonero« Francisco, laut und deutlich (»a alta e inteligible voz«, $M: N^{\circ} 154,367$ ) vorgelesen (vgl. ebd.). Der edicto wird anschließend auf Befehl des Gouverneurs und Richters im Inneren der Kirche »an prominentester Stelle« $\left(\mathrm{M}: \mathrm{N}^{\circ} 155,368\right)$ beim Taufbecken aufgehängt. Das mit Schriftzeichen versehene und an diesem Ort angebrachte Papier ist ein klares Indiz für die Präsenz des absenten Souveräns, dessen Stimme sich nach dem lauten Vorlesen notwendigerweise verflüchtigt. Durch das Anbringen an der genannten Stelle wird es zum komplexen Bedeutungsträger: Die weltliche Macht erhebt ihre Stimme aus dem Herzen der kirchlichen Macht, die Kirche gibt dem König Raum; Ort, Papier und Schriftzeichen verschmelzen so zu einem wirkungsvollen Symbol mit hohem Wiedererkennungseffekt. Jeder Blick darauf lässt alle genannten Aspekte der Bedeutung aufleuchten.

Doch kommen wir nun zum Text des Edikts, der wie die anderen Texte durch einen sehr geringen Abstraktionsgrad geprägt ist; es wird versucht, jede denkbare Einzelklage möglichst konkret zu benennen, wie um die Gewähr dafür zu schaffen, dass der oder die Urheber dieser potentiellen vorgebrachten Vergehen abgeurteilt und die Taten geahndet werden:

Yo, el Licenciado Juan Pérez de Tolosa, Juez de Residencia y Gobernador en esta Provincia de Venezuela y Cabo de la Vela por Su Magestad, hago saber 
a todos los vecinos y moradores de toda esta provincia de Venezuela y sus comarcas que por mandado de Su Majestad y los Señores de Su Muy Alto Consejo de las Indias soy venido a visitar esta provincia y cumplir de justicia a todos los que vinieron a pedir y hacer satisfacción a todos los justamente querellosos de todos los agravios, fuerzas y molestias o prisiones, injusticias, quitamientos de haciendas, que hubieren hecho, permitido o consentido expreso o tacitamente todos los gobernadores, tenientes suyos, alcaldes ordinarios, alguaciles mayores o menores y a todos los capitanes generales, tenientes suyos u otros cualesquier capitanes y escribanos y oficiales que hayan sido o son en ésta dicha provincia y sus límites después acá que Bartolomé Belzar y su compañía entraron en esta dicha provincia por mandado de Su Magestad por tanto, todos los que se quisieren venir a querellar o pedir justicia a todos los indios que forzosamente son tenidos y ocupados contra las ordenanzas de Su Magestad, vengan a pedir justicia ante mí que yo les oiré y guardaré en toda su justicia y a las personas pobres y necesitados mandaré y haré que no se les lleve derecho, la cual dicha justicia han de venir a pedir ante mí dentro de cien días que corran desde diez días de mes de junio con apercebimiento que pasado el dicho término no serán más oídos ${ }^{19}(M$ : $\left.\mathrm{N}^{\mathrm{o}} 154,367\right)$.

Zur Erinnerung: Dieser Text wird erst am 16. Juni 1546 öffentlich ausgerufen beziehungsweise ausgehängt, also nachdem Tolosa bereits von den Enthauptungen gehört hatte und nachdem bereits einige Klagen eingegangen waren (siehe Zeile 5 des zitierten Textes). Hierin könnte der Grund liegen, dass die möglichen Klagegründe so konkret aufgezählt werden: »Verletzungen«, »Gewaltanwendungen«, »Belästigungen«, »Gefangennahmen«, »Rechtswidrigkeiten « und »Enteignungen von Haciendas« sind Begriffe, die später auch in den Aussagen im Prozess gegen Carvajal fallen und vielleicht deswegen bereits hier einfließen, weil Tolosa schon von ihnen gehört hatte. Sie konnten von den Bewohnern Coros als Anspielung auf die Taten Carvajals verstanden werden. Wie um möglichst viele weitere Bewohnerinnen und Bewohner zu einer Klage im Rahmen der Residencia zu animieren, werden die Vergehen oder Unrechtmäßigkeiten benannt. Der Fokus liegt auf dem gesamten Körper der lokalen Administration, indem alle möglichen Arten von Amtsträgern, gegen die Klage erhoben werden kann, aufgezählt werden.

In den Akten der Residencia folgen nun zwei Befragungen (interrogatorios). Im Programm der Residencia vorgesehen wären natürlich die Urteile über die Amtsführung der einzelnen Magistrate, gegen die in den 90 Tagen der Erkun- 
dung von Bewohnern und Bewohnerinnen des Ortes Klage eingereicht wurde. Dass Tolosa gemäß den Akten kein einziges Urteil gefällt hat, könnte ein Hinweis sein darauf, dass die Auseinandersetzung zwischen der Krone und den Welsern, bei der es auch um Entschädigungszahlungen ging, die Abwicklung des Prozesses verzögert haben könnte. Zwischen den beiden interrogatorios der Residencia liegen zwei Jahre, in denen der Juez de Residencia seine Aktivitäten auf den Kriminalprozess gegen Juan de Carvajal verlegt hat. Alle Fragen zielen auf die Erfüllung des Kronvertrags der Welser-Handelsgesellschaft und deren Funktionäre. Ohne die übergreifende politische Auseinandersetzung um die Welser gänzlich auszublenden, die mit Sicherheit in der Auseinandersetzung zwischen Hutten und Carvajal mitgespielt hat, kann an dieser Stelle nicht auf diese beiden interrogatorios eingegangen werden. Die Analyse der Akten des Kriminalprozesses wird punktuell darauf zurückkommen.

Die beiden Prozesse - die Residencia zur Amtsausübung der Welser und der Kriminalprozess gegen Carvajal - wurden zwar getrennt geführt, mussten einander aber dennoch gegenseitig beeinflusst haben. Sie fanden in derselben Zeitspanne, am selben Ort mit weitgehend übereinstimmendem Personal statt. Beispielsweise hatte Juan Pérez de Tolosa bereits am 10. Juni, also sechs Tage vor dem pregón der Residencia, öffentlich verkündet, dass er gegen Carvajals Untaten, die dieser »in teuflischem Geist« ausgeübt haben soll, vorgehen werde. Wenn er sechs Tage später den pregón ausrufen lässt, liegt für die Bewohner Coros eine Verbindung zwischen beiden Prozessen auf der Hand.

Das nächste Unterkapitel analysiert die Akten des Kriminalprozesses gegen Juan de Carvajal. Im Anschluss daran werden einige Aspekte der angesprochenen Verbindung zwischen beiden Prozessen genauer geklärt.

\section{Die Akten des Prozesses gegen Juan de Carvajal}

Die gesamte Akte des pleito criminal $^{20}$ geht auf das Jahr 1548 zurück, als, wie das Dokument $\mathrm{N}^{\circ} 190$ (vgl. M: 543) bezeugt, Tolosa angeordnet hatte, »eine oder zwei oder mehr Abschriften « zu erstellen. Dieses Dokument nimmt in gewisser Weise die Funktion eines Inhaltsverzeichnisses ein, indem es jedes Dokument der Akte einzeln aufzählt. Dass diese spezifische Reihenfolge explizit angeordnet wurde, macht sie zu einem zusätzlichen Bedeutungsträger. Zwei Ereignisse fehlen jedoch in der Aufzählung: Tolosas zu Beginn seiner Untersuchung in öffentlicher Versammlung gehaltene Rede zu Carvajals Un- 
taten und die Bezeugung der Verhaftung Carvajals. Überlegungen zur Frage nach dem Warum werden später in diesem Kapitel angestellt.

Die Akten des Prozesses gegen Juan de Carvajal bestehen aus 24 »Documentos« (M: $\mathrm{N}^{\mathrm{O}}$ 168-191, 465-544). ${ }^{21}$ Unverständlicherweise war den Editoren von 1977 der Status des Prozesses gegen Juan de Carvajal als Kriminalprozess nicht klar, obwohl in der Akte des Urteils der Prozess ausdrücklich als »Pleito criminal $\left(M: N^{\circ} 188,540\right)$ bezeichnet wird. Da nur eine Person verurteilt wurde, schließen die Herausgeber, dass es sich nicht um einen Juicio de Residencia gehandelt haben könne, weil diese Prozessart immer mehrere Amtsträger untersucht habe. Der Prozess gegen Juan de Carvajal müsse innerhalb des Juicio de Residencia zur Amtsführung der Welser eingeleitet worden sein (vgl. Morón 1977: 72).

Die Chronologie der Prozessschritte in den Akten entspricht nicht der Chronologie der Zeitpunkte, an denen die Schritte stattgefunden haben; Schrift und Ereignis beziehungsweise das Datum des Schreibens und das Datum der Prozesshandlung klaffen auseinander. Das liegt unter anderem daran, dass manchmal die einzelnen Schritte in einem Dokument bezeugt werden, auch wenn sie an verschiedenen Tagen vollzogen wurden. So werden beispielsweise die Vereidigungen dreier Zeugen vom 30. Juni, 7. und 8. Juli 1546 in einem Dokument zusammengefasst (in diesem Fall $\mathrm{N}^{\mathrm{o}} 170$, 470). Weil die Personen nicht immer eingeführt beziehungsweise Sprecherwechsel nicht immer kenntlich gemacht werden, fällt es bisweilen schwer, die Referenzen der Pronomen zu bestimmen. Die Texte enthalten keinerlei Satzzeichen. Auch die intratextuellen Verweise durch Worthülsen wie »dicho escribano« (>besagter escribano<) oder »dicha ciudad« (〉besagte Stadt ), die konstant wiederholt werden, prägen die Akten und lassen diese zu typischen Merkmalen werden:

Y después de lo susodicho en la dicha ciudad de Coro a veinticinco días del dicho mes de junio del dicho año, el dicho Señor Juez dijo que mandaba y mandó a mí el dicho escribano saque un traslado o dos, o más, de la dicha información para la enviar ante su Majestad; testigo Alonso Pérez de Tolosa y Bartolomé García, contador de Su Majestad vecinos y estantes en esta dicha ciudad de $\operatorname{Coro}^{22}$ (M: $N^{0} 181,503$; Hervorhebungen SC).

Es handelt sich dabei um die Formeln, wie sie die bereits diskutierten Manuale und Handreichungen enthielten, die im ganzen Reich seit Jahrhunderten kursierten und den Schreibern als »compendium of useful forms notaries needed to know to do their job well« (Burns 2010: 29f.) für die Redaktion ihrer 
Texte zur Verfügung standen. Sie sollten sicherstellen, dass die verwendete Sprache den offiziellen Standards der Amtsprache entsprach. So verliehen die Formeln und Modelle dem Dokument Autorität. Die Kehrseite bringt Kathryn Burns mit den Worten José Bonos auf den Punkt: Der Gebrauch der Manuale "favored the multiplication of irrelevant clauses, and the maintenance of antiquated ones out of servile addiction « (Bono 1999: 45, zitiert nach Burns 2010: 39). Dass viele überflüssige Sätze produziert werden, darf jedoch nicht dazu verleiten, sie zu 〉überlesen dige Aufmerksamkeit geschenkt werden, um die Machart des Textes genauer bestimmen zu können. Das kann nur in einer detaillierten textnahen Lektüre gelingen, was auf den folgenden Seiten unternommen werden soll.

Während im eben zitierten Ausschnitt die Verbindung »dicho Señor Juez« eindeutig den Richter Juan Pérez de Tolosa meint, referiert »dicho escribano « auf den escribano des vorhergehenden Textes, der in diesem Fall aber die Referenz nicht preisgibt. Die Spur verliert sich, wenn sich die Lesenden auf die Suche nach dem Namen des Schreibers machen, zumal es mehrere von ihnen gibt. Wenn Pronomen thematisch verwendet werden - die Referenz des Pronomens wird nicht durch intratextuelle Bezüge hergestellt, sondern durch das Thema -, birgt die Decodierung einige Unsicherheiten. Das gilt auch im Dokument $\mathrm{N}^{\circ} 181$ (vgl. 492f.), in dem die Rede des Richters vor öffentlicher Versammlung in indirekter Rede konstruiert wird; beim Übergang zum nächsten Inhalt wird das Pronomen el beziehungsweise die Form der dritten Person verwendet, obwohl inzwischen die Referenz vom Angeklagten Juan de Carvajal zum Richter Pérez de Tolosa gewechselt hat: Carvajal

con diabólico espíritu sin tener causa ni razón les cortó las cabezas y algunos de los que con ellos venían son llegados a esta ciudad destruidos y perdidos y otros tienen en prisiones y se teme que hará lo mismo de ellos y porque él [Juan Pérez de Tolosa; SG] por el cargo que de su Majestad tiene entiende ir en persona a poner remedio a tan grandes crueldades pidió a mí el dicho escribano asentase letra por letra todo lo que los testigos que ante mí, de oficio tomase y examinase, dijeran ${ }^{23}$ ( $M$ : $N^{0} 181,493$; Hervorhebung SG).

Diese Schwerfälligkeiten des Textes können in der Textart beziehungsweise in deren Produktionsmechanismus begründet oder aber auf die mangelhaften fachlichen Fähigkeiten des konkreten escribano zurückzuführen sein. Vor allem in entfernteren Provinzen in der Peripherie war eine gute und solide Ausbildung der escribanos und der Richter keine Selbstverständlichkeit, wie 
seinerzeit Gabriel Monterroso in seiner Handreichung Practica Civil, y criminal, e instruction de scrivanos (vgl. 1563) beklagte:

[I]n many lower jurisdictions (especially where the judges hold no degree, are not instructed in the style and practice of Civil and Criminal suits, and are ignorant of the law), the entire administration of justice depends on the notary (whose ignorance often impeds Justice, harms the polity, and makes lawsuits infinite and immortal). (Zitiert nach Burns 2010: 31)

Das ganze Schriftbündel der Akten des Kriminalprozesses entstammt der Feder des escribano Juan de Quincoces de Llana; wie er im letzten Dokument (vgl. $\left.M: N^{\circ} 191,544\right)$ berichtet und bezeugt, hat er es auf Geheiß des Richters Juan Pérez de Tolosa ins Reine geschrieben und zu einer Akte zusammengestellt. Da dieses abschließend zusammenfassende Dokument Einblick gewährt in die Machart des Schreibens, wird es an dieser Stelle wiedergegeben:

Y después de lo susodicho en el dicho Asiento del Tocuyo en veintitres días del mes de enero de mil quinientos cuarenta y ocho años el dicho Señor Gobernador []uan Pérez de Tolosa; SC] dijo que mandaba y mandó a mí el dicho escribano saque y haga sacar de este proceso un traslado, o dos, o más, del nombramiento de Fiscal hecho el dicho Juan Deldua Alguacil Mayor, y querella por él dada contra el dicho Juan de Carvajal y del pedimento hecho por Caspar Fernández Procurador Ceneral de la ciudad de Coro con las informaciones sobre ello dadas y por su merced hechas y tomadas por ante Bartolomé García y Ramos Dargañaras [sic!] escribano de oficio y pareceres dados por oficiales y otras personas en Coro en el dicho proceso con lo por su merced proveído cerca de ello y del mandar dar la ropa y otras cosas de socorro a la gente y tasación y repartimiento que en ello y de ello se hizo que en el dicho proceso está y del mandamiento para prender con la Capitulación y conciertos pasados entre los dichos Carvajal y Felipe de Hutten e instrucción falsa y de las preguntas y confesión del dicho Carvajal con el auto que fue mandado se declarase y declaración que a él hizo con el testimonio de la sentencia y ejecución de ella y auto de declaración y confesión que al pie de la horca hizo y declaró y lo de todo por testimonio signado en manera que haga fe donde quiera que pareciere y fuere presentado por cuanto para poderse sacar todos los procesos para los poder llevar ante su Majestad en limpio no hay papel en este Asiento ni se puede haber y lo firmó de su nomber [wohl: nombre; SC], testigos Melchor Grubel Alcalde Ordinario y ]uan de 
Cisneros estantes en este Asiento. El Licenciado de Tolosa, Juez ${ }^{24}\left(M: N^{0} 190\right.$, 543f.).

Die ersten drei und die letzten vier Zeilen bringen das Schreibunternehmen auf den Punkt: Von diesem »Prozess« (»de este proceso«, Zeile 3) soll mindestens eine »Abschrift« (»traslado«, Zeile 3) erstellt werden. Im Gegensatz zum deutschen Wort »Prozess« kann das spanische proceso für den Prozess oder für die Prozessakten stehen. ${ }^{25}$ In diesem Fall referiert es auf die Akten, denn eine »Abschrift« kann nur von einem Schriftstück, nicht aber von einem Prozess im Sinne einer Handlungsfolge erstellt werden. Die Ambiguität des Wortes im Spanischen ist interessant; sie weist auf die gegenseitige Abhängigkeit, aber eben gleichzeitig auch auf die grundsätzliche Verschiedenheit der beiden Aspekte hin: Die juristischen Akten können nur im Zuge der juristischen Handlungen entstehen (vgl. Vismann 2012: 403f.). Handlung und Schrift hängen zusammen; das eine kann ohne das andere nicht existieren.

Zwischen dem ersten und dem letzten Abschnitt (Zeilen 4-13) wird die Struktur der Akten angekündigt, die im Folgenden in übersichtlicher Darstellung präsentiert wird. Zur besseren Orientierung werden die Daten hinzugefügt:

1. Ernennung von Juan Deldua zum Vertreter de Anklage (»nombramiento de Fiscal«, Zeile 4); 30. Juni 1546

2. Juan Delduas Anklageschrift gegen Juan de Carvajal (»querella«, Zeile 4); 30. Juni 1546

3. Appellation des procurador general der Stadt Coro, Gaspar Fernández, vor Gericht (»pedimento«, Zeile 5); 1. Juli 1546

4. die vor den Schreibern Bartolomé García und Ramos Dargañaras eingeholten Informationen (Zeugenaussagen; Antworten zu den von Gaspar Fernández eingebrachten fünf Fragen; »informaciones«, Zeile 6); 1. Juli 1546

5. beratende Versammlung verschiedener Amtsträger und anderer Personen aus Coro ("pareceres«, Zeile 7); 3. Juli 1546

6. Befehl, Kleider und andere Hilfsgüter zu sammeln, zu taxieren (Wert schätzen) und den Teilnehmern der Expedition, auf der Carvajal festgenommen werden soll, zu verteilen (»tasación y repartimiento«, Zeile 9); 4. Juli 1546

7. Haftbefehl gegen Carvajal (»mandamiento para prender«, Zeile 10); 8. Juli 1546 
8. nach Carvajals Verhaftung am 26. August 1546 in seinem »cofre de flandes « gefundener Friedensvertrag vom 29. April 1546 zwischen Hutten und Carvajal (»Capitulación y conciertos«, Zeile 10)

9. 'gefälschte ${ }^{26}$ Instruktion vom 13. Dezember 1544 zur Ernennung von Carvajal als Gouverneur (»instrucción falsa«, Zeile 11)

10. Fragenkatalog, der Richter Pérez de Tolosa dem Angeklagten vorlegte (»preguntas«, Zeile 11)

11. Carvajals Antworten und Geständnis (»confesión«, Zeile 12); 11. September 1546

12. Urteil (»sentencia y ejecución«, Zeile 13); 16. September 1546

13. Geständnis Carvajals am Fuß des Galgens (»confesión que al pie de la horca hizo«, Zeilen 12f.); 17. September 1546

Die Nummern 8 und 9 sind Abschriften von Dokumenten, die in anderen Situationen als im Prozess gegen Carvajal zustande gekommen sind und die eine gewisse Relevanz bezüglich des zu beurteilenden Falls haben. Hierbei hatte der Richter Anweisung gegeben, beide Dokumente in die Akten aufzunehmen und sie abzuschreiben (vgl. $\mathrm{M}: \mathrm{N}^{\mathrm{O}} 182,504$ ). Wie eingangs bereits angemerkt, ist dagegen erstaunlicherweise kein einziges Dokument zu finden, das den Akt der Verhaftung Carvajals durch Pérez de Tolosa bezeugen würde. Dieses Ereignis wird im Dokument $N^{\circ} 182$ (504) mittels eines Partizips übersprungen: »estando preso el dicho Juan de Carvajal «. ${ }^{27}$

Nach der Beschreibung der äußeren Struktur der Akten werden nun einzelne Zeugenaussagen besprochen, um daran anschließend das interrogatorio, das Juan de Carvajal vorgelegt wurde, seine Antworten, sein Geständnis und abschließend das Urteil und die Urteilsvollstreckung zu analysieren. Die Darstellung der entsprechenden Dokumente folgt der Chronologie, wie sie im Verlauf des Prozesses generiert wurden, und nicht der Reihenfolge, in der sie Tolosa angeordnet hatte. Damit wird sichtbar, inwiefern die Platzierung der einzelnen Dokumente in der Chronologie innerhalb der Akte bedeutungstragend ist.

\section{Inoffizielle öffentliche Anklage durch Juan Pérez de Tolosa}

Die Rede des Juan Pérez de Tolosa vom 10. Juni 1546 in öffentlicher Versammlung (vgl. M: $N^{\circ}$ 181, 492f.; Schmitt/Simmer 1999: 87f.) wird vom Schreiber Ramos Dargañarás protokolliert. Wie erwähnt, hatte Richter Tolosa keine Anweisung gegeben, dieses Dokument in die Akte aufzunehmen. Hatte er seiner 
Rede keinen offiziellen Stellenwert zugewiesen? Wollte er sie im Nachhinein verschweigen? Wie kam der Schreiber aber schlussendlich dazu, sie abzuschreiben und in die Akte zu integrieren? Die Gründe können vielfältig sein. Solche Ungereimtheiten - das immerhin ist festzustellen - erinnern daran, dass Quellen wie diese Akte unsere Fragen nicht in einfacher Weise beantworten, sondern im Gegenteil Fragen eröffnen und diese teilweise unbeantwortet lassen.

Der Schreiber berichtet, der Richter habe nach der Übernahme der Amtsstäbe dieser Statthalterschaft (»después de haber tomado las baras de la dicha Gobernación«, M: $\left.\mathrm{N}^{\circ} 181,492\right)$ gesagt, es sei ihm zu Ohren gekommen, dass ein gewisser Juan de Carvajal unter Vortäuschung seines Amtes als Gouverneur und Juez de Residencia viele Untaten begangen habe: Carvajal »so color de Gobernador y Juez de Residencia había hecho muchas extorsiones y molestias, fuerzas y robos, sediciosamente había sacado la mayor parte del pueblo en muy grave deservicio de Su Majestad $\aleph^{28}\left(\mathrm{M}: \mathrm{N}^{\circ} 181,492\right)$. Damit aber nicht genug; richtig »teuflische« Absichten hätten zu dem geführt, was »vor zwanzig oder dreißig Tagen« mit Philipp von Hutten und Bartholomäus Welser geschehen sei:

no contento con haber usado de las dichas maldades viniendo de camino Felipe de Huten y Bartolomé Belzar, el mozo, hijo de Bartolomé Belzar, Adelantado ${ }^{29}$ de la dicha Provincia, puede haber veinte o treinta días, poco más o menos, acompañado de todos los bulliciosos que para ello le dan favor y ayuda que consigo trae los salteó y a los susodichos y a otros principales con ellos pospuesto el temor de Dios y el Emperador y Rey Nuestro Señor con diabólico espíritu sin tener causa ni razón les cortó las cabezas ${ }^{30}\left(\mathrm{M}: \mathrm{N}^{0} 181\right.$, 492f.).

Wie gesagt steht das Ergebnis der Untersuchung für den Richter schon am 10. Juni fest. Es ist für ihn klar, dass Carvajal vorsätzlich, aus niederen Beweggründen und ohne äußeren Anlass seinen Opfern die Köpfe abgeschlagen hat. Der Schuldspruch Carvajals ist schon gefällt, bevor Carvajal angehört werden kann. Die Richtung, wie die Zeugen aussagen sollen, ist damit vorgegeben. Im Verlauf der Rede wird klar, dass Tolosas Informationen von einigen Männern stammen, die Carvajal entkommen konnten. Weitere Männer halte dieser immer noch gefangen. Um, wie Tolosa sagt, weiteres Unheil zu vermeiden, plant er bereits am ersten Tag seiner Anwesenheit in Coro, Carvajal nachzuziehen und ihn zu verhaften. Nicht zuletzt stellt er sich damit als treu- 
en, handlungsfähigen und -willigen Diener des Königs und >Retter in letzter Not der Bewohnerinnen und Bewohner der Provinz dar:

[A] Igunos de los que con ellos venían son llegados a esta ciudad destruidos y perdidos y otros tienen en prisiones y se teme que hará lo mismo de ellos y porque él por el cargo que de Su Majestad tiene entiende ir en persona a poner remedio a tan grandes crueldades pidió a mí el dicho escribano asentase letra por letra todo lo que los testigos que ante mí, de oficio tomase y examinase, dijeran. ${ }^{31}\left(M: N^{0} 181,493\right)$

Er beabsichtigt, »Abhilfe zu schaffen« (»poner remedio«) - was auch immer das heißen mag. Er erteilt dem escribano den Auftrag, wortwörtlich (»letra por letra« - »Buchstabe für Buchstabe«) aufzuschreiben, was die Zeugen zu den schrecklichen Taten aussagen werden. Interessanterweise interessiert sich Pérez de Tolosa nicht nur für die Umstände der Enthauptungen, sondern auch dafür, welche »Länder, Reiche und Provinzen« (Übersetzung Simmer, Schmitt/Simmer 1999; »tierras, reinos y provincias «, $M: N^{\circ} 181$, 493) Hutten und seine Truppe während ihrer entrada entdeckt haben, möglicherweise sogar für potentielle Goldfunde. Damit schreibt sich die Forderung Tolosas in die übergeordneten Ziele im Unternehmen der europäischen Expansion nach Übersee ein.

Im Folgenden werden einzelne Zeugenaussagen gelesen, kommentiert und miteinander in Beziehung gebracht.

\section{Aussage des Cristóbal de Aguirre}

Diese erste zu den Akten genommene Aussage vom 10. Juni 1546 liest sich anfangs wie ein Expeditionsbericht; erst etwa bei der Mitte des Textes nähert sie sich der Tötung Philipps von Hutten und Bartholomäus Welsers auf Befehl Juan de Carvajals. Dies zeigt sich auch im Tempo des Erzählens: Während die erste Hälfte die Ereignisse der entrada vom Start im August 1541 bis März 1546 in geraffter Form abdeckt, beanspruchen die restlichen drei Monate, die entsprechend genau textuell konstruiert werden, die gesamte zweite Hälfte des Berichts. Das Erzähltempo wird in diesem Teil durch zahlreiche szenische Redewiedergaben verringert. In dieser zweiten Hälfte werden keine Daten mehr angeführt wie in der ersten, sondern nur annähernde Angaben wie »drei Tage«, »am dritten Tag« (Übersetzung Simmer, Schmitt/Simmer 1999; vgl. M: $\mathrm{N}^{\mathrm{O}}$ 181, 497) oder Ähnliches. Bezüglich der Produktionsweise des Textes lässt sich sagen, dass das detaillierte Nachzeichnen der Route wohl kaum einer 
mündlichen Erzählung des Zeugen Aguirre entstammt, sondern dass diese Teilakte wohl eher auf einem schriftlich festgesetzten Bericht des Zeugen basiert. Wenn dies zuträfe, wäre der Satz des Schreibers: »testigo suso dicho presentado para la dicha información dijo y depuso [...] lo siguiente« $\left(\mathrm{M}: \mathrm{N}^{\mathrm{O}}\right.$ 181, 493; Hervorhebung SG) eine reine Floskel.

Aguirre war Teilnehmer der Hutten-entrada und von Beginn an, beim Aufbruch aus Coro am 1. August 1541, dabei. Der erzählte Zeitraum erstreckt sich über knapp fünf Jahre; das Erzählen orientiert sich an der Reiseroute und der Chronologie der Ereignisse.

Desde allí partieron pasado el mes de enero y caminaron febrero y marzo y abril por la falda de una gran sierra que dicen que se nombra de los Coyones y atraviesa las partes del Perú e invernaron en las riberas de un río que se dice Cazanare por donde entró Lope de Montalvo al Nuevo Reino y llegado el mes de agosto del dicho año de cuarenta y dos llegaron a otro río muy caudaloso que se dice Opia [...]. Pasado este gran río en canoas que de nuevo hicieron hallaron mucha tierra llana y parte montuosa tierra de mucho maíz y cazabe y tierra de contratación de sal ${ }^{32}$ (494).

Die Beschreibung der Route hangelt sich entlang der Namen von Sierras, Flüssen und Völkern. Die Truppe muss viele Entbehrungen, Hunger und Kämpfe mit »indios« über sich ergehen lassen. Einmal werden »cristianos« von 10.000 »indios« ohne Vorwarnung überfallen; obwohl die Angreifer erfolgreich in die Flucht geschlagen werden konnten, sei dies der Anfang vom Ende gewesen: »en esta provincia dice que comenzaron a haber gran daño y principio de su pérdida $\aleph^{33}\left(\mathrm{M}: \mathrm{N}^{\mathrm{o}} 181,495\right)$. Viele Pferde seien ihnen gestorben; erst als sie herausgefunden hätten, dass dies eine Folge des Salzmangels war, hätten sie sich erholen können. Ähnliche Erzählungen prägen auch die Briefe Philipps von Hutten. Hier wie dort unterbrechen ethnographische Beschreibungen das Voranschreiten der Handlung:

[E] traje de los indios [caquetíos] es ningun porque todos ellos andan desnudos cubiertas sus venganzas, las armas con que pelean son las ofensifas dardos y lanzas de una madera aguda y muy enconosa, adargas de cueros gruesos como dientes, llámanse los indios guaipis aqui se hallaron collares y joyas de fino oro ${ }^{34}\left(M: N^{\circ} 181,494\right)$.

Gold - wie in den Hutten-Briefen ist es auch hier das große Thema. ${ }^{35}$ Der Fund brachte in diesem Fall ebenso nichts ein, denn die caquetios bezogen das Gold nach ihrer Aussage von anderen Völkern. Auch die Fährte von »Chris- 
ten«, die sich aus dem Reino de Granada auf die Suche nach der Provinz mit dem vielversprechenden Namen »El Dorado« $\left(\mathrm{M}: \mathrm{N}^{\circ} 181,494\right)$ machten, von denen Hutten und seine Männer über Dolmetscher von »indios« erfuhren, verlor sich. Eine Vorhut der Truppe unter der Führung Pedro de Limpias' erkämpfte sich nach einem Scharmützel mit Choques von deren »principal« namens Capta zwei große Kronen aus Feingold ( $\left.M: N^{\circ} 181,495\right)$. Wie bei der von Hutten beschriebenen Hohermuth-entrada fragen die Expeditionsteilnehmer sofort nach der Herkunft des Goldes, worauf Capta gemäß Aguirres Darstellung nach bekannter Manier auf ein anderes Reich verweist: "preguntado [Capta] de donde había habido las dichas coronas dijo que las hubo de las amazonas donde afirmó haber estado ${ }^{36}\left(\mathrm{M}: \mathrm{N}^{\circ} 181,495\right)$. Hutten habe sich fast eineinhalb Jahre später, im November 1544, aufgemacht, Captas Hinweis auf die Amazonen zu überprüfen: Er hätte mit seinen Leuten von einem Volk, das sich "mayas « nenne und von denen er leicht verletzt worden sei, erfahren, dass »en la junta del río dicho de Guacaya y Montoya que se llama abajo Mamia estaba la población de las Amazonas y Ocuarica el Dorado muy cerca « ${ }^{37}\left(\mathrm{M}: \mathrm{N}^{\mathrm{o}}\right.$ 181, 496). Hutten habe sich mit der Hälfte seiner Leute dahin geschleppt, dies jedoch nur, um kurze Zeit später aus Mangel an Kräften wieder umzukehren:

[D]ejada allí [en la provincia de los Guaipis] la mitad de la gente se fue con la otra parte a tener certeza o procurar de tenerla en sí [wohl: si] era verdad lo que le había dicho el indio de las amazonas y así volvió a los omegoas que es una nación de indios altos y ligeros de grandes fuerzas y muy belicosos tienen poblaciones grandes de a más de mil bohíos y muchas, detuvieron solamente una noche y und día porque no les dió a más lugar la fortaleza y poder la gente y así se volvieron a la compañía que dejaron con saber que muy cerca de allí era la nación de las amazonas ${ }^{38}\left(M: N^{0} 181,496\right)$

Die wiederholt eingestreuten, kurzen ethnographischen Beschreibungen wie hier des Volkes der Omaguas - verbinden diese Zeugenaussage mit den Briefen Huttens. Sogar die Kannibalismusikonographie wird aufgerufen:

[L] legaron a un río llamado Papame cerca de Navidad del dicho año de cuarenta y dos donde hallaron gente belicosa bárbaros que se comen los unos a otros y los vivos comen a los que naturalmente se mueren y esto se vió porque en toda esta tierra se halló sepultura de difunto y porque los mismos indios se lo dijeron y manifestaron así. ${ }^{39}\left(\mathrm{M}: \mathrm{N}^{0} 181,495\right)$

Weiter geht es im Text mit Beobachtungen aller Art, geäußert mit unverkennbarer Distanz zu den Einheimischen, die den Diskurs des Kolonialhe- 
rren markiert: »Hay en esta provincia mucho cazabe y maíz y comen de todo animal vivo aunque sean culebras y arañas las cuales hay en gran manera grandes, juegan en su pelea de rodelas de palo mua grandes anchas y gruesas y tienen una manera de dardos de madera y las puntas de huesos de animales $\ll^{40}\left(M: N^{\circ} 181,495\right)$.

Aguirres Aussage ist der einzige Text der Prozessakten, der das Merkmal der ethnographischen Beschreibungen aufweist. Diese Tatsache könnte ein Hinweis darauf sein, dass der Richter Tolosa außer über die Ereignisse um die Enthauptungen auch über die entrada informiert werden wollte. Expeditionsberichte - so kann man vermuten - rufen solche Beschreibungen als typische Merkmale dieser Textart auf. Diese Erklärung lässt allerdings die Folgefrage unbeantwortet, weshalb nur die Aussage Aguirres dieses Merkmal aufweist.

Hutten hatte nach dem Bericht Aguirres ein weiteres Mal - das war Ende des Jahres 1544 - knapp sein Ziel verfehlt, das Goldreich El Dorado zu finden. Damit nähert sich die Erzählung möglicherweise dem an, was Diego Ruiz de Vallejo in seinem Brief als "gran noticia« bezeichnete: Die Neuigkeit einer Entdeckung, die Hutten von seiner entrada mitgebracht haben soll. Aufgrund der schwindenden Kräfte hätten Hutten und seine Kompanie Anfang 1545 den Beschluss gefasst, nach Coro umzukehren, "para dar cuenta de sus trabajos a Su Majestad « ${ }^{41}\left(\mathrm{M}: \mathrm{N}^{\circ} 181,496\right)$. Doch dieses Vorhaben sollte, wie bereits aus der Lektüre der Briefe Huttens hervorgegangen ist, zum Stolperstein der gesamten Unternehmung werden. Zunächst wurden die Männer von den vielen Wassern des Flusses Pauta aufgehalten. Der Einbruch des Winters im Mai zwang sie, Rast einzulegen. Wie schlimm es um sie stand, macht Aguirres Bericht klar: Ein Voraustrupp sollte nach Coro eilen und »dar noticia de como era vivo ${ }^{42}$ (ebd.) Der Trupp bestand aus 20 Mann und war der Führung von Bartholomäus Welser unterstellt. Pedro de Limpias, ein Kenner der Sprache der »indios«, schickte Hutten ebenfalls mit. In Barquisimeto sollte der Trupp auf ihn, Hutten, warten (vgl. M: $\mathrm{N}^{\mathrm{O}} 181,497$ ).

Die Darstellung des Leidens und der redlichen Bemühungen Huttens wird den Lesenden plastisch vor Augen geführt. Das Bild Philipps von Hutten als unschuldiges Opfer wird im Verlauf der Erzählung weiter ausgebaut. Folgt man dem Bericht, kam es unter den 20 Männern, die Hutten vorausgeschickt hatte, zu einer Meuterei gegen Bartholomäus Welser, angezettelt von Pedro de Limpias, der sich offen Huttens Befehl widersetzte, nach Coro zu gehen und ein Lebenszeichen von ihnen zu senden: »[D]eterminó el Pedro de Limpias de se apartar con seis compañeros a la parte de Barquisimeto con intención de embarcarse por aquella parte a la isla de Curazao y en ninguna 
manera volver a Coro ${ }^{43}\left(M: N^{\circ} 181,497\right)$. Im Gegensatz dazu blieb Welser bei den Kranken und Schwachen (»enfermos y flacos«, ebd.) und wird dadurch ähnlich wie Hutten als treuer Hauptmann ausgezeichnet.

Als Krönung der moralischen Verwerflichkeit der Gegenseite verbrüdert sich Limpias mit Carvajal, sobald diese kurze Zeit darauf zusammentreffen. Aguirres Bericht bringt Limpias direkt in Verbindung mit Carvajals Gräueltaten, die bereits an dieser Stelle vorweggenommen werden: »[A] sí siguiendo su camino llegaron a dar en manos de Juan de Carvajal y su gente con el cual el dicho Pedro de Limpias se confederó y aún se cree que tomó avisos por ejecutar las crueldades que después ejecutó« ${ }^{44}\left(\mathrm{M}: \mathrm{N}^{\mathrm{0}} 181,497\right)$.

Dieser Aussage zufolge hat Carvajal gewusst, dass Hutten Welser in Barquisimeto wieder treffen wollte, nachdem er ihn vorausgeschickt hatte. Implizit wird damit zum Ausdruck gebracht, dass Carvajal dieses Wissen ausnutzte, als er Juan de Villegas auf die Suche nach der Truppe Philipps von Hutten schickte. Als Villegas den Hauptmann nach 40 Tagen nicht getroffen habe, habe Villegas ihm zwei Briefe am Weg hinterlassen und mitgeteilt, »como le había estado aguardando cuarenta días y que su merced se diese prisa que en Barquisimeto sería muy bien recibido «"45 ( $\left.M: N^{0} 181,497\right)$. Wie dieser ssehr gute Empfang، endete, wissen zum Zeitpunkt der Aussage alle Lesenden des Textes: mit seiner Enthauptung.

Als Hutten die Briefe entdeckt habe, habe er sich sofort auf den Weg gemacht und Villegas schnell eingeholt, und zusammen hätten sie Carvajals Lager in Barquisimeto erreicht. Drei Tage lang hätten sich Hutten und Carvajal und alle Männer nett und lustig (»graciosamente«, ebd.) unterhalten. Von Bartholomäus Welser habe Hutten aber erfahren, dass Carvajal ihn nicht habe weiterziehen lassen. Daraufhin habe er Boten zu Juan de Carvajal gesandt und ihn gebeten, dass "porque él y Bartlomé Belzar venían muy fatigados, enfermos y rotos, y lo mismo toda su compañía y tan largos trabajos y caminos que no les pusiese embargo ni estorbo en su camino ${ }^{46}$ ( $M: N^{\circ} 181,497 f$.). Er, Hutten, müsse unbedingt nach Spanien ziehen, »a dar cuenta a Su Majestad de su tan larga y trabajosa jornada con tanta pérdida de su hacienda y salud « ${ }^{47}\left(M: N^{0} 181,498\right)$. Dieser Bericht aus dem Munde Huttens, die seine und seiner Leute Not darstellen, lässt Carvajal nach Aguirres Darstellung offensichtlich kalt. Auch den Vorschlag Huttens, ihre beiden Amtsverfügungen $\mathrm{zu}$ vergleichen, um zu sehen, wem von beiden tatsächlich Befehlsgewalt zukommt, lehnt er rundweg ab. Seine Äußerungen sind, im Gegensatz zu denen Huttens, kurz und bündig und ersticken das Ansinnen Huttens im Keim: Carvajal »respondió que en ninguna manera les dejaría ir« und »respondió 
que no daría tal licencia y que antes les mandaba que so pena de muerte no saliesen de donde él estuviese ${ }^{48}\left(M: N^{\circ} 181,498\right)$. Ein letzter Versuch Huttens, ihre Verfügungen zu vergleichen - ein Zeichen seiner Loyalität, weil die Verfügungen ja letztlich auf den König zurückgehen -, wurde von Carvajal mit einem Ausbruch von »Wut und Zorn« und einem tätlichen Angriff beantwortet: Hutten

le tornó a replicar [a Carvajal; SG] lo que le había rogado y requerido con las provisiones que mostró que se viesen las suyas y las que el le mostraba y que no le hiciese agravio ni le pusiese impedimento a la su suya [sic!] partida a lo cual el dicho Juan Carvajal con mucha furia y enojo respondió que no quería y juntamente con esto echó mano de los pechos del dicho Capitán Felipe de Huten diciendo sed preso ${ }^{49}\left(M: N^{0} 181,498\right)$.

Dieser Haftbefehl, in direkter Rede wiedergegeben (»sed preso«, ebd.), wirkt hart und gewalttätig, was Huttens Gegenangriff mit Degen und Umhang (»espada y capa«, ebd.), Zeichen der Wehrhaftigkeit, als gerechtfertigt erscheinen lässt. Carvajal und Villegas hätten sich in ihre Hütten geflüchtet, und Hutten und seine Leute hätten sich auf den Weg gemacht, wie um weitere Auseinandersetzungen zu vermeiden. Mit Kriegsgeheul und einer mächtigen Truppe sei Carvajal über die friedlich rastenden Leute Huttens hergefallen: »[A] poco rato del lugar donde estaban aposentados salió el dicho Juan Carvajal con buen tropel de gente armada y a son de guerra arremetieron contra el dicho Antonio [wohl: Felipe] y Bartolomé Belzar y compañía «50 $\left(M: N^{\circ} 181,498\right)$. Dieses Mal gelang es den Überfallenen noch, ihre Angreifer in die Flucht zu schlagen. Ebenfalls zur Opferrolle passend muss Welser den Weg zu Fuß fortsetzen, denn »un Almarcha Aguacil Mayor que es de Carvajal dió dos lanzadas a su caballo y así le faltó « ${ }^{51}\left(\mathrm{M}: \mathrm{N}^{\mathrm{o}} 181,499\right)$.

Der Text, der bisher explizit nur das von Aguirre Beobachtete wiedergegeben und zwischen den Zeilen Carvajal als böswilligen Übeltäter charakterisiert hat, greift nun den Ereignissen vor und unterstellt Carvajal, schon früh die Tötung seiner Gegner geplant zu haben: Als Hutten auf $30 \mathrm{zu}$ Carvajal gehörende Berittene trifft, entwaffnet er diese, »temiéndose que llegada aquella gente que el dicho Juan Carvajal seguiría su intento en seguirlos y maltratarlos y matarlos como después lo hizo ${ }^{52}\left(\mathrm{M}: \mathrm{N}^{0} 181,499\right)$. Auf dieser Grundlage erscheinen die von Carvajal initiierten Friedensverhandlungen und die Unterzeichnung des Friedensvertrags, den Carvajal und 30 Männer aus seiner Truppe signieren, mehr als arglistig. Denn der Vertrag sollte Grundlage dafür sein, dass diejenigen, die mit Hutten weiterziehen wollten, dies ungehindert 
tun und mit Gottes Segen (»con la bendición de Dios«, ebd.) den Weg fortsetzen könnten. Diejenigen dagegen, die bei Carvajal bleiben wollten, sollten dies ebenfalls tun können, und sie sollten in der Truppe gut aufgenommen und gut behandelt werden (»buena compañía und tratamiento«, ebd.). Wiederum lässt der Text die Lesenden im Voraus erahnen, was Hutten später widerfahren wird: Dieser habe den Weg durch die Sierra genommen, weil er ihn für sicherer und kürzer gehalten habe, und »con recelo que tenía lo que después le vino envió a este que depone con otros dieciocho compañeros a que fuesen a cortar y hacer camino de la sierra «53 $\left(\mathrm{M}: \mathrm{N}^{\mathrm{O}} 181,499\right)$. Damit kann sich Aguirre selbst als loyalen Soldaten darstellen, auf den Philipp von Hutten sich verlassen hatte.

Das ist jedoch nicht alles. Die Tatsache, dass dem Opfer Philipp von Hutten vorausahnende »Besorgnis« unterstellt wird, »die er wegen dem hatte, was ihm später widerfuhr«, widerspricht der Darstellung, dass er nichts Böses ahnend in der Hängematte lag, als Carvajal ihn überfiel. Hier kristallisiert sich im Text möglicherweise die bereits erwähnte Tatsache heraus, dass die Schuld Carvajals von Anfang an feststand und dass sie in diesem Kriminalprozess nur noch untermauert werden sollte. Die penetrante Hervorhebung der moralischen Schlechtigkeit Carvajals weist auf den Umstand hin, dass >Wahrheitsfindung nicht im (modernen) Sinne einer Suche nach den tatsächlichen Begebenheiten betrieben wurde.

Und wiederum ist es gemäß dieser Aussage Carvajal, der die mit dem vereinbarten Friedensvertrag eingekehrte Eintracht hinterlistig zerstört, diesmal allerdings endgültig. Aguirre ist kein direkter Augenzeuge der Hinrichtung, weil er ja von Hutten zusammen mit 18 Leuten vorausgeschickt worden war. Um den Tathergang wiederzugeben, muss er sich also auf andere Quellen stützen. Interessant ist nun, wie er in direkter Rede wiedergibt, was Diego Ruiz de Vallejo ${ }^{54}$ erzählt hatte:

[Y] así este testigo se partió adelante y dejó al dicho General con hasta veintidos compañeros y continuó la sierra haciendo su camino y al cabo del tercero día estando este testigo y sus compañeros durmiendo llegó con mucha congoja y pasión Diego Ruiz de Vallejo que es uno de los que estaban en el campo y compañía de Carvajal y le dijo como el dicho Juan Carvajal [sic!] con toda su compañía había dado sobre el dicho Felipe de Huten y Bartolomé Belzar y compañía y los habían prendido y que él se había escapado con una lanzada que traía bien señalada y de gran herida en la cabeza y así este testigo y sus compañeros y el dicho Vallejo con harto trabajo y mala ventura 
vinieron huyendo por los montes bravíos y han aportado [wohl: llegado] en esta ciudad de $\operatorname{Coro}^{55}$ (M: $\left.\mathrm{N}^{0} 181,499\right)$.

Der in Angst und Schrecken versetzte Ruiz de Vallejo sei im Lager »mit viel Leid und Schmerz« (»con mucha congoja y pasión«) angekommen, während Aguirre und seine 22 Gefährten gerade geschlafen habe, und habe von der Gefangennahme Huttens und Welsers und davon, wie er vor Carvajal geflüchtet sei, berichtet, wovon seine gut sichtbare große Wunde am Kopf Zeugnis ablege. So sei er, Aguirre, mit seinen Gefährten und zusammen mit Ruiz de Vallejo mit Mühe und Not (»con harto trabajo y mala ventura«) durch die wilden Berge geflohen und vor etwa 20 Tagen hier in Coro eingetroffen.

Der von Aguirre zitierte Zeuge Ruiz de Vallejo ist, wie wir aus seinem in Kapitel 6 beschriebenen Brief wissen, seinerseits kein direkter Augenzeuge der Enthauptungsszene. Um seine Aussage glaubhafter zu machen, zitiert Aguirre zwei weitere Zeugen, Perico und Magdalena, zwei christianisierte Indiosklaven des Philipp von Hutten, die der Enthauptung beigewohnt haben und nach ihnen »in dieser Stadt« eingetroffen seien:

los cuales han dicho y dicen públicamente que después de haber preso el dicho Juan de Carvajal a los dichos Felipe de Huten y Bartolomé Belzar y compañía hizo cortar las cabezas de noche a la luna en el campo a los dichos Felipe de Huten y Bartolomé Belzar y a dos gentiles hombres que se nombraban el uno Romero y el otro Plasencia y que allí los enterraron con las manos en una barranca de un arroyo y pusieron una cruz de palo junto a su sepultura y a los otros compañeros los llevaron atados con cadenas y malos tratamientos y los dichos esclavos estuvieron escondidos hasta que pasó todo lo suso dicho y tuvieron lugar de se venir por la montaña con harto trabajo hasta llegar en esta ciudad de Coro donde al presente están y que esto es lo que pasa de este caso y sabe y tiene memoria y firmolo de su nombre. Cristóbal de Aguirre ${ }^{56}$ ( $M: \mathrm{N}^{0} 181,499 f$.).

Neben den auffälligen erzählerischen Elementen - Enthauptung »bei Mondschein«, dem mit bloßen Händen ausgehobenen Grab, das Grab mit einem Kreuz versehen und die aus dem Verborgenen beobachtenden Sklaven - gibt uns die Passage möglicherweise einen Hinweis darauf, wie die Erzählungen, die schließlich im Prozess protokolliert wurden, ihren Anfang nahmen. Wenn Aguirre am 10. Juni zu Protokoll gibt, dass Perico und Magdalena ihre Beobachtungen in der Öffentlichkeit erzählt hätten und immer noch erzählten (»han dicho y dicen públicamente«), war die Hinrichtung der vier Männer 
auch außerhalb der offiziellen Zeugenvernehmung unter den Bewohnern und Bewohnerinnen von Coro im Gespräch. Dies ist interessant, weil offenbar die Erzählungen nicht erst vor Gericht produziert wurden, sondern schon vorher in anderen, uns nicht näher bekannten, vielleicht informellen Konstellationen Form angenommen haben und damit zu etwas >Besonderem`, Erzählwürdigen wurden.

An dieser Stelle ist die Eröffnung einer kleinen Klammer angebracht. Eine - zugegebenermaßen anachronistische - Parallele lässt sich zu dem von Michel Foucault (vgl. 1973) beschriebenen Fall Pierre Rivière ziehen. Foucault trägt in seinem Buch alle Texte und Dokumente über den vierfachen Mörder im Frankreich des 19. Jahrhunderts zusammen und zeigt, wie der Diskurs ein >alltägliches` (da nicht singuläres) Ereignis zu etwas Außergewöhnlichem macht. Nach Foucault müssen die Erzählungen (»narrations«, Foucault 1973:269) mit Elementen, Figuren, Namen, Handlungen, Dialogen und Objekten bestückt werden. Solche Erzählungen könnten möglicherweise die Rolle eines Transformators einnehmen, der das Alltägliche zum historisch Bemerkenswerten macht. Diese Transformation setze sich aus drei Teiloperationen zusammen :

Et dans cet échange s'effectuent trois opérations essentielles: ce que les gens ont vu de leurs yeux, ce qu'ils se racontent de bouche à oreille, tous ces récits qui courent dans les limites d'un village ou d'un canton, en prenant la forme de l'extraordinaire, deviennent racontables à tous, universellement transcriptibles; les voilà dignes enfin du papier imprimé : passage à l'écriture. (Ebd.: 269f.)

Es braucht Augenzeugen und ihre Erzählungen, die mündlich weitergereicht werden und die innerhalb des Dorfes kursieren. Das Beobachtete wird erzählbar und nimmt erst damit eine Form an, die verschriftlicht werden kann. Das Gerücht verwandelt sich so in eine feststehende, ein für alle Mal fixierte Neuigkeit. ${ }^{57}$ Das Dorf und seine Bewohnerinnen und Bewohner würden so jenseits der institutionalisierten Macht zu autonomen Geschichtsschreibenden:

Par là enfin, le village ou la rue se trouvent, par eux-mêmes et sans intervention extérieure, produire de l'histoire; et celle-ci en retour marque de son passage instantané les dates, les lieux et les hommes. Il n'a pas été besoin d'un roi ou d'un puissant pour les rendre mémorables. Tous ces récits racontent une histoire sans maîtres, peuplée d'événements frénétiques et 
autonomes, une histoire en dessous du pouvoir et qui vient buter contre la loi (Foucault 1973 : 270).

Was unterscheidet jedoch diesen Fall vom Fall Carvajal? Die `Gerüchte`, die in Coro über Carvajal kursieren, stehen unter starkem Einfluss der Rede des einflussreichen Juez des Residencia vom 10. Juni. Er gibt die Richtung vor, wie Carvajals Taten einzuordnen sind. In der Folge richten sich die Darstellungen der Ereignisse nach seiner Vorgabe wie einem Magneten aus. Bemerkenswert indes erscheint die Tatsache, dass die einzigen direkten Augenzeugen der Tat zwei Indiosklaven sind. Der >Beweis`, dass Carvajal Hutten und Welser enthauptet hatte, wird lediglich unter Berufung auf zweite und dritte Quellen angetreten.

Wie oben bereits erwähnt, zeigt die Aussage Cristóbal de Aguirres die Eigenheit, dass wiederholt ethnographische Beschreibungen eingestreut werden. Dieses Merkmal verbindet den Bericht mit Huttens Briefen: Auch Hutten unterbricht seine Erzählungen immer wieder mit solchen Exkursen. Möglicherweise lassen sich diese mit einer Kreuzung mit anderen, auf Schrift besierenden Textgenres erklären: Aguirre wird vor der Aussage als »natural de la Universidad de Irun« $\left(M: N^{\circ} 181,493\right)$ unter Eid genommen; er gehört also wie Hutten den letrados, den Gelehrten an, also derjenigen Gruppe unter den Konquistadoren, die eine universitäre Bildung mitbringen.

Gleichzeitig geben die Einsprengsel eher den Ton einer schriftlich verfassten als einer mündlich vorgetragenen Aussage wieder. Denn vor Gericht, wenn es um die Erzählung der Ereignisse und nicht zuletzt um die Verteidigung der eigenen Handlungsweise während der Kämpfe zwischen Hutten und Carvajal geht, sind solche Abschweifungen vom eigentlichen Thema wenig sinnvoll beziehungsweise schlecht vorstellbar. Inwiefern die Merkmale der Schriftlichkeit jedoch im Verlauf der Schlussredaktion durch den escribano einflossen, lässt sich kaum eruieren.

\section{Aussage des Diego Ruiz de Vallejo}

Morón und sein Team hatten Vallejos Aussage vom 10. Juni 1546 für die Edition von 1977 nicht transkribiert. Grundlage der Analyse dieser Zeugenaussage ist daher das Manuskript aus dem AGI, ${ }^{58}$ dessen Scan mir in einem PDF-Dokument vorliegt. Anstelle der Aussage von Vallejo verweist die Edition Morón auf die Transkription der vorhergehenden Aussage - das ist die oben beschriebene Aussage Aguirres - mit der Bemerkung: »Ver declaración 
del testigo anterior. Igual ${ }^{59}$ (M: 500). Doch was genau heißt»[i]gual«? Worin besteht die Übereinstimmung, und wie weit geht sie? Ist von einer inhaltlichen oder sprachlichen Übereinstimmung die Rede? Vergleicht man die beiden Texte, stellt man tatsächlich eine teilweise wortwörtliche Übereinstimmung in der Wiedergabe der Version der Magdalena fest (siehe Anhang, Tabelle 1). Ähnliches zeigt der Vergleich der Zeugenaussage von Diego Ruiz de Vallejo mit seinem Brief: beide Schriftstücke stimmen streckenweise wörtlich überein (siehe Anhang, Tabelle 2). Diese Tatsache, die sich hinter dem beinahe leichtfertig gesetzten und nicht weiter hinterfragten Hinweis: »Igual«, verbirgt, stellt die Vertrauenswürdigkeit der Akte grundsätzlich in Frage: Wenn wörtliche Übereinstimmungen an verschiedenen Stellen in den Akten eines Prozesses bestehen, heißt das, dass der Schreiber zumindest bei der Endredaktion mehrmals von ein und demselben Dokument abgeschrieben haben musste. Mit anderen Worten: Die Rückbindung der Aussagen an einzelne Personen, die in den Akten als Zeugen angegeben werden, steht auf wackeligen Beinen.

Andererseits zeigt der Vergleich der Aussage Vallejos mit seinem später verfassten Brief auch, dass gewisse Eigenheiten seiner Sprache beide Texte kennzeichnen. Sie sind beispielsweise beide durch einen markanten Einsatz direkter Figurenrede geprägt. Wenn nun die Frage nach der sStimme stellt wird, wenn festgestellt werden soll, wie und in welchem Ausmaß die ursprünglichen Formulierungen in den Zeugenaussagen durch den Prozess des Aufschreibens durch den escribano verändert wurden, kann gesagt werden, dass sich gewisse Eigenheiten der Erzählweise der Aussagenden textuell manifestieren. Die Zeugen prägen der resultierenden Aussage bis zu einem gewissen Grad ihre persönliche Note auf.

\section{Aussage von Magdalena und Perico}

Die Aussage der »India Magdalena« vom 13. Juni 1546 wurde bereits in der Einleitung beschrieben, weil sich darin zentrale Problemstellungen und Einsichten dieser Studie kristallisieren (siehe die Ausführungen dort). An dieser Stelle soll nur kurz auf die Rolle eingegangen werden, die die Aussage innerhalb der ganzen Serie von Aussagen einnimmt. "Magdalena « figuriert als Zeugin, die offenbar mit einem im Vergleich zu den anderen Zeugenbefragungen eingeschränkteren Fragekatalog konfrontiert wurde. In dieser Art und Weise der Befragung manifestiert sich die Sicht und das Handeln des Kolonisators: Richter Pérez de Tolosa befragte die »India cristiana y ladina y 
criada del dicho Capitán Felipe de Huten $\aleph^{60}\left(\mathrm{M}: \mathrm{N}^{\circ} 181,500\right)$ nur zum Vorgang der Hinrichtung (»para averiguación de solo el acto de la muerte«, ebd.). Ihre Erzählung diente in den Aussagen von Cristóbal de Aguirre und Diego Ruiz de Vallejo als Informationsquelle, über die weder Aguirre noch Vallejo verfügten, denn beide waren keine direkten Augenzeugen der Enthauptung.

Primeramente dijo que conoció al dicho Felipe de Huten y Bartolomé Belzar y que conoció a Plasencia y Romero difuntos porque ésta que depone fue criada de más de diez años del dicho Felipe de Huten y a los otros conoció de vista y habla q que lo que sabe del caso es que viniéndose su[s] caminos los dichos difuntos con hasta veinte compañeros, poco más o menos, y estando alojados y descansando de muchos trabajos que traían del luengo camino, a puesta del sol el mes que pasó estando la luna en el mismo ser que hoy día trece de junio tiene llegó mucha gente de caballo y de a pie sobre ellos entre los cuales venía Juan de Carvajal y Pedro de Limpias y Nájera y Fuenmayor y Luis Fernández a los cuales conocía de antes y otros muchos que no conocía y arremetiendo con el dicho Felipe su compañía prendieron a los dichos Felipe de Huten y Bartolomé Belzar y Romero y Plasencia y les ataron los manos y brazos atrás y atados así los detuvieron hasta bien tarde de la noche y ya casi al medio de la noche cortaron la cabeza primeramente sobre una piedra a Romero y luego tras él a Plasencia y tras él a Bartolomé Belzar y luego tras él a Felipe de Huten y cortadas las cabezas juntándolas con los cuerpos los enterraron en un ribazo de un arroyo y asieron de los compañeros y maltratándolos se volvieron con ellos y los más andaban buscando por los otros compañeros que se habían ido huyendo y que esto es lo que pasa y la verdad para el juramento que hizo y no firmó porque dijo que no sabía escribir, firmolo de su nombre del dicho Señor Licenciado de Tolosa, Cobernador. El Licenciado de Tolosa $^{61}$ (M: $\left.N^{0} 181,501\right)$.

Die Aussage Pericos, des Ehemanns von Magdalena, wurde vom Notar nicht transkribiert, weil sie "wörtlich und inhaltlich" mit derjenigen Magdalenas übereingestimmt habe (»siendo preguntado por la vía de lo que sucedió y acaeció cerca del caso dijo a la letra y en sustancia lo que la dicha Magdalena dijo $\left.{ }^{62}, M: N^{\circ} 181,501\right)$. Diese Behauptung ist bemerkenswert, denn wie oben ausgeführt ist es tatsächlich kaum vorstellbar, dass zwei verschiedene Zeugen dieselbe Aussage im selben Wortlaut machen. Es handelt sich also um einen drastischen Eingriff in den >Urtext $<$ der >Zeugenaussage<, der exemplarisch vor Augen führt, welche Transformationen solche Aussagen bei der Einschreibung in den kolonialen bürokratischen Apparat erfahren können. 


\section{Aussage des Miguel de Barrientos und Frutos de Tudela}

Obwohl die Zeugenaussagen vom 10. Juni die Untaten Carvajals allesamt $\mathrm{zu}$ bestätigen scheinen, protokolliert der escribano de Sus Majestades, Bartolomé García, am 29. Juni, Juan Pérez de Tolosa habe verkündet, dass die von ihm zur Enthauptung Huttens, Welsers und zweier weiterer Spanier gesammelten Informationen ihren Tod nicht bestätigt hätten (vgl. $\mathrm{M}: \mathrm{N}^{\circ} 179,486$ ). Um über sichere Informationen bezüglich ihres Todes zu verfügen, nehme er die Aussage eines gewissen Miguel de Barrientos auf, der an jenem Tag »aus dem Landesinneren« (»de tierra adentro«, $\mathrm{M}: \mathrm{N}^{\mathrm{o}} 179,487$ ) aus Carvajals Lager kommend in Coro angekommen sei. Barrientos Aussage vom 29. Juni 1546 bestätigt den Tod der vier Männer; was neu hinzukommt, ist die Information, das Carvajal ihnen die Beichte verweigert und dass ein »negro« die Köpfe mit vier oder fünf Machetenschlägen abgeschlagen habe. Barrientos war einer der 17 »cortadores« (ebd.), eines Vorauskommandos, das Hutten zwecks Freilegung des Weges vorangeschickt hatte. Wie fast alle Zeugen vor ihm war also auch er nicht direkter Augenzeuge des Geschehens, auch er zitiert andere Beobachter:

[L]a noche que [Carvajal] desbarató al dicho Felipe de Huten y Capitán Bartolomé Belzar y los otros compañeros los degolló sin consentir que se confesasen y les dijeron asimismo que al Bartolomé un negro de cuatro o cinco golpes con un machete lo degollaron y que a los demás los cortaron las cabezas de la misma manera ${ }^{63}\left(\mathrm{M}: \mathrm{N}^{0} 179,487\right)$.

Frutos de Tudela (vgl. M: $\left.\mathrm{N}^{\circ} 180,488-492\right)$, »Priester und Beschützer der Indios« (»cura y protector de los indios«, $\mathrm{M}: \mathrm{N}^{\mathrm{o}} 180,488$ ), war unmittelbar Zeuge der Enthauptungsszene. Sein Bericht ist im wahrsten Sinne des Wortes ein Augenzeugenbericht. Diesem legt er eine Art Geschichtenschema zugrunde, indem er den Moment vor dem Überfall als betont friedlich ausschmückt: ${ }^{64}$ Hutten habe sich aufgrund des Friedensschlusses mit Carvajal in falscher Sicherheit gewähnt und friedlich in seiner Hängematte gelegen, als Carvajal mit seinen Leuten über ihn und seine Leute hergefallen sei (vgl. $\mathrm{M}^{\circ} \mathrm{N}^{\circ} 180$, 491). Der Zeuge scheint sehr eingenommen zu sein von dem, was er berichtete: Ganze drei Mal fallen die Worte "cortar las cabezas«, und die >Toten baten unter lautem Stöhnen, beichten zu dürfen. Tote stöhnen nicht - dass die Schilderung vom Ablauf her nicht stimmen kann, hat offenbar weder den Schreiber während der Aussage gestört noch denjenigen, der die Schlussredaktion durchgeführt hat: 
[V]ino, ya que se quería poner el sol, el dicho Juan de Carvajal con mucha gente guerra a pie y a caballo armados y estando así seguros dió en ellos y prendió al dicho Felipe de Huten y al dicho Capitán Bartolomé Belzar y a otros siete, a los cuales echó en cadenas con colleras al pescuezo vituperando las personas de Felipe de Huten y Bartolomé Belzar diciendo que eran herejes y traidores y desde ha media hora que los hubo preso les hizo cortar a dos negros las cabezas por el colodrillo como a traidores y lo mismo hizo a un Plasencia y a otro Romero y al tiempo que los mandó cortar las cabezas todos los dichos muertos con grandes voces y gemidos pedían confesión y penitencia de sus pecados rogándoles hasta tanto no los matase y el dicho Carvajal respondió en presencia de este testigo que no quería que se confesasen y este testigo como cura propio de ellos requirió al dicho Carvajal a voces publicamente que mirase que aunque tenía poder sobre los cuerpos que no le tenía sobre las ánimas que eran divinas que los dejase confesar y respondió el dicho Carvajal otra vez que no quería que se confesasen y mandó con amenazas que echasen a este testigo de allí y en esta sazón les cortaron las cabezas como tiene declarado donde dejaron estar las cabezas y cuerpos vilmente entre los caballos y pies de la gente hasta que este testigo a la mañana los pidó enterrar y el dicho Carvajal respondió que los cuerpos que los enterrasen que las cabezas quería llevar al Tocuyo que es donde estaba su asiento y llevó presos a otros ocho compañeros en cadenas con colleras vilmente habiéndoles quitado así a éstos como a los muertos y a otras personas sus haciendas y repartiéndolas entre los que con él venían ${ }^{65}$ (ebd.).

Erst nach der Aufnahme dieser Aussage erhob der Vertreter der Anklage (eine Art Staatsanwalt) seine Anschuldigungen, die jedoch - wir erinnern uns - als erstes Dokument in den Akten verzeichnet ist.

\section{Anklage des Juan Deldua}

Die Anklage des Juan Deldua (M: $\mathrm{N}^{\mathrm{o}}$ 169, 467-469; deutsch in Schmitt/Simmer 1999: 111-114) wurde von ihm am 30. Juni 1546 verlesen. Seine Rede - seine »verdadera relación« $\left(M: N^{\circ} 169,467 ;\right.$ »wahrhafter Bericht«, Übersetzung Simmer, Schmitt/Simmer 1999: 111) - wird in direkter Form wiedergegeben. Es ist eine Zusammenfassung aller bis dato eingeholten Informationen. Zur Erinnerung: Es ist im ersten Dokument der Akten enthalten, nach den einführenden Worten des Schreibers Juan de Quincoces de Llana zu seinem Vorgehen bei der Schlussredaktion und nach der Urkunde mit der Ernennung 
Juan Delduas zum Vertreter der Anklage. In der Anklage zählt Deldua »los casos de sus hechos nefandos y abdominables de tiranías a crueldades así contra cristianos como contra indios vasallos de Su Majestad y de paz « ${ }^{66}$ (ebd.) auf. Es ist unverkennbar, dass Carvajal im schlechtesten Licht dargestellt werden soll. Nach der Auflistung zahlreicher Untaten, die alle dem Dienste Seiner Majestät zuwiderlaufen, folgt die Darstellung des Konflikts zwischen Hutten und Carvajal:

[E]n un día del mes de mayo próximo pasado de este presente año de mil quinientos cuarenta y seis años y sobre asechanza habiéndole asegurado para que le viniese alevosamente y a traición lo soltó [wohl: salteó] y prendió y teniendo presos mandó a sus negros que para el efecto traía que les cortasen las cabezas a los dichos Felipe de Huten y Bartolomé Belzar y a otros que asimismo hizo matary pidiéndole confesión cada uno de ellos habiendo clérigo presente no consintió que se confesasen ni les dió copia ni traslado de sus culpas ni les oyó sus defensas que era obligado a recibir por toda ley divina y humana, y así los mató e hizo matar contra toda razón y justicia siendo como eran los muertos muy leales servidores y criados de Su Majestad caballeros y de muy grande arte y nación ${ }^{67}\left(\mathrm{M}: \mathrm{N}^{0} 169,468\right)$.

Der Text wartet gleich mit einer ganzen Serie von verabscheuungswürdigen Merkmalen auf, die Carvajal als heimtückischen Verräter charakterisieren sollen: »asechanza« (Falle), »alevosamente« (heimtückisch) und »traición« (Verrat). Die Bemerkung, dass Carvajal zwei »negros« eigens zum Zwecke einer Enthauptung mitgeführt habe, soll die Vorsätzlichkeit seiner Tat belegen. Carvajals Befehl zur Hinrichtung Philipps von Hutten, Bartholomäus Welsers und zweier Spanier erscheint umso heimtückischer, als keine Vorgeschichte der Zuspitzung des Konflikts angeführt wird. Als weitere Untat wird ihm vorgeworfen, die dem Tode Geweihten nicht zur Beichte zugelassen zu haben, obwohl ein Geistlicher zugegen war. Gott und die Krone erscheinen wiederum als Machtkonglomerat, denn Carvajal hat nach Darstellung der Anklage gegen die Gesetze beider (»ley divina y humana«; »contra toda razón y justicia«) verstoßen. Es scheint erwiesen, dass Carvajals Handlungen gegen Seine Majestät gerichtet waren, weil er die von höchster Stelle erlassenen Gesetze verletzt hat. Dieser Eindruck wird noch verstärkt, indem seine Opfer als treue Diener Seiner Majestät und Angehörige einer "großen Nation« dargestellt werden. Die Taten wiegen aus der Sicht Delduas so schwer, dass er für Carvajal die schlimmste Todesstrafe fordert, die das Gesetz vorsieht: 
$[\mathrm{H}]$ izo otros robos y fuerzas manifiestas y de presente las hace y continúa no contento con las pasadas por todo lo cual cosa y parte de ellas haber hecho y cometido y por la menor de ellas merecer padecery ser condenado a muerte turpisima y otras penas de aplicación de bienes sobre lo cual y cada cosa y parte de ello pido ser hecho cumplimiento de justicia y que habiendo lo suso dicho por cierto y verdadero Vuestra merced por su sentencia le condena a la más grave muerte que en derecho se hallare por tan graves hechos y delitos ${ }^{68}$ (M: $\left.\mathrm{N}^{0} 169,468\right)$.

Diese Strafen verlangt er auch für all jene, die Carvajal dazu geraten und ihn unterstützt hätten. Erstaunen mag die Aussage Delduas, dass er seine Anklage nicht aus Böswilligkeit (»no la hago maliciosamente«, ebd.) erhebe, sondern weil sich seine Taten tatsächlich so ereignet hätten. Warum betont er dies ausdrücklich? Als Vertreter der Anklage hat er ja gerade die Pflicht, Delikte zu verfolgen. Dass er nun anführt, dies nicht boshaft zu tun, könnte auf den Improvisationscharakter der Prozessabwicklung hindeuten. Die Rollen der einzelnen Figuren wurden kurzfristig und nur für die Dauer dieses einen Prozesses festgelegt. Dies muss zur Folge gehabt haben, dass sowohl seitens des Personals als auch der Bewohner und Bewohnerinnen wenig Professionswissen vorhanden war, was wiederum erklären könnte, weshalb Vorgehensweisen und Prozessschritte explizit und in schwerfällig redundanter Weise benannt werden, die gesetzlich vorgegeben und damit im Grunde genommen selbstverständlich sind. Fasst man hingegen das Wort "maliciosamente« als juristische Formel auf, könnte genau das Gegenteil gefolgert werden: Deldua handelt professionell, indem er situationsangemessene Formeln einzusetzen versteht. Das Wort tritt nämlich auch an späterer Stelle im Prozess während der Befragung Carvajals auf. Sowohl Carvajal - ein ehemaliger Notar - als auch Juan Pérez de Tolosa benutzen den Begriff an zentraler Stelle der Verhandlung: Carvajal lehnt Tolosa mitten in seiner Befragung als Richter $a b$, möchte den ganzen Prozess für nichtig erklären und beim König Beschwerde einlegen. Die Akten halten fest, dass er geschworen habe, die Berufung nicht "maliciosamente« gemacht zu haben (»el dicho Carvajal dijo que juraba y juró en forma de derecho que la dicha recusación no la hacía maliciosamente«, M: $\mathrm{N}^{\mathrm{o}}$ 186, 532). Gemäß den Akten ernannte Tolosa daraufhin zwei »acompañados«, Begleiter, und führte an, Juan de Carvajal habe ihn »maliciosamente« als Richter abgelehnt (ebd.).

Am Ende seiner Rede fordert Juan Deldua Tolosa auf, Juan de Carvajal an jenen Ort zu folgen, wo dieser sich mit seinen Leuten - alles Delinquenten - 
befinde, damit nicht noch mehr und schlimmere Dinge passieren würden und um die totale Zerstörung dieser ganzen Provinz zu verhindern (vgl. $\mathrm{M}: \mathrm{N}^{\circ}$, 469). Damit spielt er Tolosa in die Hand, da er ihm das Argument liefert, das er braucht, um sein Vorhaben - die Expedition nach El Tocuyo, wo sich Carvajal aufhält - einzuleiten, bei den Bewohnern vor Ort durchzusetzen und später vor dem König zu rechtfertigen.

\section{Aussage des Juan de Quincoces de Llana}

Am gleichen Tag wird derselbe Juan de Quincoces de Llana, der als Schreiber des Prozesses fungiert, als Zeuge für »oben Gesagtes« $\left(M: N^{\circ} 171,470\right)$ herangezogen. Wie mag es wohl für den offiziellen escribano gewesen sein, als Zeuge auszusagen? Seiner Aussage vom 30. Juni 1546 zufolge zog er fünf Jahre zuvor mit Philipp von Hutten ins Landesinnere, um die Provinz zu entdecken; er stand also dadurch sauf der richtigen Seites. Im Moment der Enthauptung war er, will man der Transkription seiner Aussage Glauben schenken, nicht zugegen: Er berichtet vom Überfall durch Carvajal, und nach etwa einer Stunde habe er erfahren (»le dijeron«, $\mathrm{M}: \mathrm{N}^{\circ} 171,472$ ), dass Juan de Carvajal Hutten, Welser, einem Plasencia und einem Romero »die Köpfe abschlagen ließ« (ebd.). Was seine Aussage als Angehörigen des bürokratischen Apparats auszeichnet, ist seine ansonsten nirgendwo verzeichnete Bemerkung, dass er weder gesehen noch erfahren noch davon gehört habe, dass den Opfern der Prozess gemacht worden sei, wie es das Gesetz verlange (vgl. ebd.).

Die Forderung, Carvajal zu verhaften, erfolgt notabene vor der Anhörung des Angeklagten. Einmal mehr zeigt sich, dass es nicht um die Wahrheitsfindung über die genauen Vorkommnisse ging; es müssen andere Ziele im Vordergrund gestanden haben. Was man mit Sicherheit sagen kann, ist, dass die Einigkeit unter den Bewohnern und Bewohnerinnen der Provinz erhöht hat und sie damit gestärkt aus der Situation hervorgingen. Dies lässt sich an den in den wichtigen Punkten gleichlautenden Zeugenaussagen ablesen, aber auch an den Protokollen über die Vorbereitungen der Verhaftung Carvajals vom 3. Juli. Zuvor wird jedoch noch der offizielle Schreiber des Prozesses, Juan de Quincoces de Llana, als Zeuge aufgerufen, und Gaspar Fernández, der Coros Siedler und Konquistadoren während des Prozesses vertritt (vgl. M: $\mathrm{N}^{\mathrm{O}}$ 171, 474), verkündet am 1. Juli 1546 sein Ersuchen um Carvajals Bestrafung nach Recht und Gesetz mit weitgehend identischer Begründung. Dass beide unterschiedslos dieselben Haftforderungen stellen, zeigt erneut, dass der Prozess nicht in erster Linie dazu dienen sollte, Carvajals Schuld zu bewei- 
sen, sondern Konsens unter den Bewohnern herzustellen. Wie Deldua fordert Fernández, dass Tolosa möglichst viele Kriegsleute versammle, um mit ihnen Carvajal zu verfolgen und zu verhaften (vgl. M: $\mathrm{N}^{\circ} 172,476$ ). Er fügt fünf Fragen an, die unter anderem die Ausstattung der Männer vor Ort betreffen. So lautet etwa Frage 2, ob die Zeugen wüssten, dass die Soldaten in Coro »weder Waffen noch Kleidung noch andere Dinge« (ebd.) besäßen, um den Zug ins Landesinnere anzutreten. Damit läutet er die Organisation der Verhaftungsexpedition nach El Tocuyo ein.

Am 3. Juli 1546 versammelte Juan Pérez de Tolosa 15 Amtsträger von Coro, um sich ihrer Gefolgschaft zu versichern (vgl. Schmitt/Simmer 1999: 114). Der Schreiber Ramos Dargañarás las nach eigener Aussage die Anklage und das Ansuchen vor (vgl. M: $\mathrm{N}^{\circ} 175$, 479). Tolosa habe vor ihm, dem Schreiber, gesagt, dass er kürzlich von Spanien - »de los Reinos de España« - in diese Provinz gekommen sei, um hier Gott und Seiner Majestät zu dienen und den Folgen der Delikte Carvajals Abhilfe zu schaffen (vgl. M: $\mathrm{N}^{\circ} 175,479 f$.). Dafür bindet er nun die Männer in seine Planung ein, indem er sie als Kenner der Verhältnisse vor Ort (»personas que saben las cosas de la tierra«, $M: N^{\circ} 175,480$ ) um ihre Meinung fragt, was nun zu tun sei, womit Gott und seiner Majestät am meisten gedient sei. Die Männer seien einhellig (»de un voto y parecer«, ebd.) dafür, protokolliert der Schreiber weiter, dass Tolosa sehr schnell (»con toda prisa«, ebd.) die Stadt Coro verlassen solle, um zu verhindern, dass Carvajal aus der Provinz ausreise, weil man es als gesichert ansehe, dass Carvajal dies vorhabe. Um diesen Zug durchführen zu können, bräuchten die Spanier Ausrüstungsgüter, denn sie seien so arm, dass sie sich nicht einmal einkleiden könnten. Daher müsse er, Tolosa, sie auf Kosten der Beschuldigten ausrüsten. Alonso Pérez (der Bruder von Juan Pérez de Tolosa), der in Besitz von Kleidern, Waffen und anderen Gegenständen sei, wird tags darauf unter Androhung einer Strafe von 500 Pesos (vgl. M: $\left.\mathrm{N}^{\circ} 176,481\right)$ befohlen, dass er alles abgeben solle, was für die Ausrüstung der Kriegsleute geeignet sei. Der Schreiber hält fest, dass er Alonso Pérez diese Anweisung verkündet und dieser geantwortet habe, er sei bereit, seiner Majestät zu dienen. Die gesammelten Gegenstände werden vor Zeugen und dem Schreiber taxiert und an die 24 Soldaten verteilt, die an der Expedition teilnehmen (vgl. $\mathrm{M}: \mathrm{N}^{\circ} 178$, 485). Der ganze Vorgang inklusive Bewertung jedes einzelnen Gegenstandes wird akribisch festgehalten. Diese Einschreibung in den kolonialen Apparat bindet die beteiligten Männer ein in das koloniale Unternehmen, was sie zu aktiven kolonialen Subjekten macht. 


\section{Aussage des Calixto Cle}

Auch dieser Zeuge gehörte zu Philipp von Huttens Truppe. In seiner Aussage vom 7. Juli 1546 berichtet er in Übereinstimmung mit Quincoces de Llana, dass Carvajal den Gefangenen eine Stunde, nachdem er sie in Ketten gelegt habe, den Kopf habe abgeschlagen lassen. Man erfährt also nicht, ob Calixto Cle die Enthauptung als Augenzeuge beobachtet hat. Er habe vor der Enthauptung im Auftrag der >Toten Philipp von Hutten und Bartholomäus Welser den Priester Frutos de Tudela geholt, damit dieser ihnen die Beichte abnehmen könne. Carvajal habe den Geistlichen aber weggeschickt. Calixto Cle seinerseits will gesehen haben, dass Carvajal und seine Leute Hutten alle Güter entzogen haben, und ihm selbst habe ein Sebastián de Almarcha einen Indio weggenommen, weil er nichts anderes gehabt habe, was man ihm hätte rauben können. In dieser Aussage manifestiert sich das Bestreben, Carvajals Grausamkeit zur Schau zu stellen: Er, Calixto Cle, habe gesehen (»vio«, M: $N^{\circ}$ 171, 474), dass Carvajal die Leichen und abgeschlagenen Köpfe der Enthaupteten »unter Hunden und zwischen den Hufen der Pferde« habe liegen lassen, »um sich grausam zu zeigen« (ebd.).

Am 8. Juli erfolgt die Ankündigung des Haftbefehls, der allerdings nicht nur gegen Carvajal, sondern gegen weitere sechs Männer ausgesprochen wird, unter ihnen Juan de Villegas und Pedro de Limpias (vgl. M: $\mathrm{N}^{\mathrm{o}}$ 182, 503f.). Am 9. Juli wird Juan Deldua von Tolosa angewiesen, ihn mit 50 Mann in die Provinz von Barquisimeto zu begleiten, wo Carvajal weile. Er, Deldua, solle Carvajal und die oben erwähnten anderen Männer verhaften und sie ihm persönlich vorführen, damit er ihnen den Prozess machen könne. Alle Spanier werden bei Todesstrafe angewiesen, dabei Unterstützung zu leisten (vgl. M: $\mathrm{N}^{\circ}$ 181, 504). Mit dieser Aktion wird die ganze Provinz einbezogen und auf ein gemeinsames Ziel hin ausgerichtet. Über Gehorsam wird Einheit geschaffen, werden die Siedler und Konquistadoren fern der Heimat zusammengeschweißt, auch wenn - aus heutiger Sicht - nicht alle Fragen geklärt wurden. Warum beispielsweise wurde von den sechs Männern, gegen die sich der Haftbefehl richtete, nur Carvajal verhaftet?

Auch fehlt, wie bereits erwähnt, ein Bericht darüber, was auf dem Zug nach El Tocuyo geschah und wie Juan de Carvajal verhaftet wurde. Dies erstaunt umso mehr, als ein solches Dokument Richter Tolosa Gelegenheit geboten hätte, sich aktenkundig als Held zu profilieren, dem es gelungen ist, die Provinz Venezuela von einem seiner schlimmsten Übeltäter zu befreien. Genau dies hat Tolosa im Brief an den König vom 15. Oktober 1546 auch getan, 
also noch vor der Endredaktion der Akten. Er hätte anordnen können, eine Kopie des Briefes in die Akten zu integrieren, so wie er auch andere Dokumente zu diesem Zweck abschreiben ließ.

Am 27. August bezeugt der Schreiber Juan Quincoces de Llana, dass Juan de Carvajal sein Geständnis abgegeben habe. Ab diesem Zeitpunkt werden alle Dokumente der Akten in El Tocuyo gezeichnet.

\section{Interrogatorio - Fragekatalog für Carvajals Vernehmung}

Als Grundlage der Analyse des interrogatorio dient Avellán de Tamayos (vgl. 1997) Transkription, die sich stärker am Manuskript orientiert als die von Morón. Im Gegensatz zum Manuskript hat die Autorin jedoch jeweils Carvajals Antworten unmittelbar anschließend an die Fragen transkribiert.

Im interrogatorio wurden Juan de Carvajal 110 >Fragen zur Beantwortung vorgelegt, Fragen, die diesen Namen jedoch nicht verdienen. Denn Fragen zielen normalerweise darauf $a b$, ein bestimmtes Wissen zu generieren. Wie folgendes Beispiel zeigt, verhält es sich im vorliegenden Fall genau umgekehrt: Das vorher durch den Richter bei den Bewohnern und Soldaten eingeholte Wissen über das Geschehen wird in die Frage verpackt, die Carvajal nur noch bestätigen oder verneinen kann (vgl. Gujer 2016:300). Carvajal wird also nicht als Wissensquelle gesehen; er soll lediglich die Richtigkeit der präsentierten Informationen bestätigen. Fast scheint es, als ob das Todesurteil schon feststeht, man aber trotzdem die Bestätigung vom Befragten braucht, damit alles seine formale Richtigkeit hat. >Wahrheitsfindung scheint nicht oberstes Ziel des Prozesses gewesen zu sein, sondern vielmehr die Wiederherstellung der Ordnung durch das Geständnis des Beschuldigten.

Trotzdem wird in diesem Teil des Prozesses ein neues Kapitel aufgeschlagen: Die juristischen und notariellen Formeln, die bisher den Text streckenweise bis zur Unverständlichkeit durchzogen, reduzieren sich hier bis auf wenige Ausnahmen auf ein Minimum. Frage Nr. 54 soll dies veranschaulichen:

Preguntado sy es cierto que luego que llegó ante él, el dicho Capitán Felipe de Uten se quitó la gorra de la cabeza y le dixo: Señor Cobernador, ya sabe vuestra merced como yo e aquestos caballeros y hermanos que aquí están avemos andado cinco años en el descubrimyento de esta Governación, donde avemos perdido muchos amigos e caballos, e ropa, y venimos destruidos y pobres, enfermos, cansados e adeudados, e como me an seydo amigos en los trabajos quyero que vayan conmigo al Puerto donde salimos a descansar 
e a que se remedien porque allí, si está Juez de Resydencia, yo quiero dar mi Resydencia e dar quenta a su Majestad e a los señores Belzares, a cuyo cargo está esta Gobernación, suplico a vuestra merced no nos lo estorbe ny nos moleste ${ }^{69}$ (Avellán de Tamayo 1997:271).

In dieser Befragung kommt erstmals der Angeklagte selbst zu Wort, was allerdings beim Richter auf wenig Interesse stößt. So bestreitet Carvajal mehrmals die in den Fragen aufgestellten Behauptungen, was jeweils keinerlei weitere Untersuchungen nach sich zieht. Im folgenden Fall wurde Carvajal beispielsweise gefragt, "sy mandó al dicho Diego Ruiz de Vallejo ahorcase al dicho Diego de la Fuente, e que azotase a Miguel de la Fuente y le desgarronase una pierna; e a Çaratán e a Rodrigo Pareja, los azotase ${ }^{70}$ (ebd.,: 261). Carvajal bestreitet dies und verweist auf ein Schreiben, das er Diego Ruiz de Vallejo gegeben habe, aus dem das Gegenteil hervorgehe (vgl. ebd.). Dieser Entgegnung wird nicht nachgegangen, das von Carvajal angeführte Schreiben wird nirgendwo kopiert und zu den Akten gelegt. Carvajals Eingabe findet keinerlei Widerhall in den Akten.

An mehreren Stellen des interrogatorio wird Carvajals Monstrosität auf drastische Weise evoziert. Ähnlich wie in der eben zitierten Frage 27 wird er in Nr. 95 gefragt, ob es wahr sei, dass er die Köpfe der vier Toten "gesalzen und gebraten « zu einem Grillfest (»Barbacoa«) auf dieses Feld bringen wollte $\left(M: N^{\circ} 185,519\right)$. Seine Antwort lautet, »dass dies nie Gottes Wille gewesen sei, sondern dass er befahl, sie zusammen mit ihren Leibern zu begraben « (vgl. M: $\mathrm{N}^{\mathrm{o}} 186,535$ ). Hier steht Aussage gegen Aussage; dass dem Vorwurf nicht weiter nachgegangen wird, hinterlässt den Eindruck, Carvajal habe tatsächlich das makabere Ansinnen geäußert beziehungsweise einen solchen Wunsch gehegt. Carvajal hat auch keine Chance, Klage beim König einzureichen, die er offiziell und formell beantragt und bezeugen lässt (Beantwortung der Frage 57, vgl. M: $\mathrm{N}^{\mathrm{O}}$ 186, 532). Zum Eklat kommt es bei den Fragen bezüglich der Enthauptung der vier Opfer. Carvajal verweigert mehrfach die Auskunft und verweist auf den Prozess, den er dazu gegen die später Enthaupteten geführt haben will, dessen Akten er dem König geschickt habe, um ihn über seine Tätigkeiten in der Provinz zu informieren (vgl. M: $N^{\circ} 186,531$ ). Doch auch nach diesen Schriften wird nicht gesucht, auch sie gehen nach dieser einen Erwähnung in den Akten unter, ohne weitere Spuren zu hinterlassen.

Nach Tolosas Aufforderung, Carvajal solle sich gemäß dem Gesetz erklären, weist ihn dieser als Richter wegen Misstrauen gegen ihn zurück. Auch den Stellvertreter, den Tolosa daraufhin ernennt, weist der Angeklagte ab mit 
der Begründung, er sei Tolosas Neffe. Den Akten gemäß schwört er nach Recht und Gesetz, dass die Richterablehnung nicht aus bösem Willen (»no la hacía maliciosamente «, $\left.M: N^{\circ} 186,532\right)$ erfolge und dass er gegen alles protestiere und alles für nichtig erkläre (»nulidad en todo«, ebd.). Er verlangt, dass dies in einem testimonio schriftlich festgehalten wird, um Klage bei seiner Majestät einzureichen. Dieser testimonio folgt unmittelbar darauf, deutlich zu erkennen an der typischen und bekannten Amtssprache (auch »officialese« genannt, Burns 2010: 146); die Sätze werden wieder umständlich und gespickt mit vorgefertigten Formeln:

En este estado en este dicho día mes y año susodicho el dicho Señor Cobernador hizo el nombramiento de acompañados que se sigue:

En el Asiento del Tocuyo de esta Provincia y Cobernación de Venezuela a veintisiete días del mes de agosto de mil quinientos cuarenta y seis años el muy Magnífico Señor Licenciado Juan Pérez de Tolosa Gobernador en la dicha Provincia por Su Majestad por ante mí Juan de Quincoces de Llana escribano de Su Majestad dijo que por cuanto hoy dicho día estando tomando su confesión a Juan de Carvajal preso, el dicho Juan de Carvajal maliciosamente le había recusado diciendo ser sospecho y que él [Tolosa] había nombrado por su acompañado a Alonso Pérez Alcalde Mayor al cual asimismo había recusado $^{71}\left(M: N^{0} 186,532\right.$; Hervorhebungen SG).

Zwei Wörter dieses testimonio verdienen Beachtung: Erstens belegt das Wort »confesión« (Geständnis) unsere Vermutung, dass die Funktion der Befragung Carvajals nicht in der Suche nach >Wahrheit < besteht, sondern dass seine Antworten bereits unter der Prämisse >Geständnis` aufgenommen werden. Zweitens das Wort »maliciosamente«: Carvajals Eingabe, dass er nicht aus bösem Willen (»no maliciosamente«) die Richterablehnung beantragt habe, wird hier ganz einfach mit der Wiederholung desselben Begriffs in Form einer Gegenbehauptung ohne weitere Begründung getilgt. Als weitere Verstärkung ernennt Tolosa zwei Männer zu seinen »acompañados« (Begleitern), die schwören, alles zu tun, wozu gute Begleiter verpflichtet seien. Drei weitere Männer unterzeichnen das Dokument als Zeugen. Nach der Einleitung dieser Maßnahmen kann nun die Befragung wieder am Punkt vor der Richterablehnung durch Carvajal ansetzen und weitergehen, als ob nichts geschehen wäre: »Y estando presentes los dichos acompañados juntamente con el dicho Señor Gobernador el dicho Carvajal respondió a las preguntas de aquí adelante « ${ }^{72}$ (M: $\left.\mathrm{N}^{\mathrm{O}} 186,532\right)$. 
Im weiteren Verlauf versucht Carvajal, die Schuld auch seinen Mitstreitern zuzuspielen. Auf die 83. Frage, wer ihm geraten habe, Hutten zu verfolgen, und wer ihm geholfen habe, ihn zu verhaften und ihm den Prozess zu machen, erwiderte er, alle, die mit ihm gekommen seien. Derjenige, der ihm geraten habe, Hutten »cinco o seis días o cuatro o cinco $\left(M: N^{\circ} 186,534\right.$ (>fünf oder sechs, oder vier oder fünf Tageく, Übersetzung SG) vorausgehen zu lassen und ihn dann zu verhaften, sei Pedro de Limpias gewesen. Überhaupt hätte er Hutten und seine Männer ohne Almarcha und Limpias niemals verfolgt. Nachdem er sie verhaftet habe, hätten alle angefangen zu schreien: »Macht ihm den Prozess! Macht ihm den Prozess! (»después que los tuvo presos comenzaron a gritar hágase justicia, hágase justicia«, $\left.M: N^{\circ} 186,534\right)$. Trotz dieser Hinweise gegen Limpias und Almarcha und obwohl gegen beide Haftbefehl erlassen worden war, wurden sie nicht verfolgt und einzig und allein Carvajal als Schuldiger festgeschrieben.

Die Befragung Carvajals ist geprägt von Wiedergaben direkter oder indirekter Figurenreden. Die Frage 90 enthält sogar ein kleines >Drama im literarischen Sinne:

Fue preguntado sy quando mataron mataron a los suso dichos, el Capitán Bartolomé Belzar le dijo: Señor Cobernador, mire vuestra merced ques on cristianos, déxeles vuestra merced confesar, y que le respondió: calla vos Bartolomé Belzar, que a vos yo os enviaré al Rey, que os Castigue. $Y$ si es que a esto dixo Sebastián de Almarcha, Alguacil Mayor que era: Señor, Vuestra Merced es el Rey e aquí no hay otro Rey, haga lo que ha de hacer, e a esto dixo: pues yo soy el Rey. Negro, corta la cabeza a Bartolomé Belzar ${ }^{73}$ (Avellán de Tamayo 1997: 282). ${ }^{74}$

Folgende Antwort hält die Akte fest: »A las noventa preguntas dixo que era tanta la grita e alboroto de la gente que no se acuerda de lo que le decían ni de lo que él dijo « ${ }^{75}$ (ebd.).

Als Zeichen höchster moralischer Verwerflichkeit steht die Aussage, dass Carvajal seine Opfer nicht zur Beichte zugelassen habe, obwohl ein Geistlicher, nämlich Frutos de Tudela, anwesend war. Frage 92 legt nahe, dass er Hutten sogar mitten in dessen Gebet köpfen ließ:

Preguntado sy es verdad que asy mismo mandó a otro negro suyo, que cortase la cabeza al Capitán Ceneral Felipe de Huten, el cual respondió que le diese confesión que era pecador y él le dixo que en el cielo se confesaría y el dicho Felipe de Hutten [sic!] puso las manos al cielo y diciendo: Yn ma- 
nus mas [wohl: tuas; SC] Domine comendo [wohl: commendo; SC] espíritum [spitritum] meum e diciendo, miserere mey, le cortaron la cabeza por el cogote. Declare lo que pasó ${ }^{76}$ (Avellán de Tamayo 1997: 283).

$\mathrm{Zu}$ seiner Verteidigung führt Carvajal an, alle, die da gewesen seien, hätten zusammen die Enthauptungen angeordnet, und in der Antwort auf Frage 92 gibt er an, "que sabe que fueron degollados todos cuatro y que con el albaroto de la gente no se acuerda ni miró las dichas palabras «77 (ebd.). Auf die Frage 90 antwortet er in ähnlicher Art und Weise, nämlich, dass er sich wegen des »Geschreis« der Leute weder an deren Worte noch an seine Eigenen erinnere. Sein Wissen in Bezug auf den Hauptvorwurf, der gegen ihn vorgebracht wird, versagt also seinen Dienst oder aber wird von Carvajal bewusst ausgelassen, um sich zu schützen. Dies könnte allerdings als Schuldbekenntnis aufgefasst werden.

Nach der Beantwortung der Fragen durch Carvajal fanden einige weitere, nicht näher erläuterte Verhandlungen der Parteien statt (vgl. $\left.M: \mathrm{N}^{\circ} 186,537\right)$. Am 11. September wurde Carvajal in einem auto (Beschluss) aufgefordert, sein Geständnis zu erläutern. Auffallend ist, dass das Interesse des Gerichts, die Beteiligung der von Carvajal erwähnten Hauptleute Pedro de Limpias und Sebastián de Almarcha zu klären, für das Schlussurteil keinerlei Rolle spielen sollte (vgl. auch Schmitt 1999: 130). Das Gericht verfolgt diese >Spur $<$ nicht weiter, was ein weiterer Hinweis darauf sein kann, dass es beim Kriminalprozess nicht primär um >Wahrheitsfindung ging, sondern auf weite Sicht um die Herstellung einer kolonialen Ordnung und Normalität.

Mit der Wiedergabe des erwähnten auto kehrt auch die verklausulierte Formelsprache des Schreibers zurück:

Y después de lo suso dicho en el dicho Asiento del Tocuyo a once del mes de septiembreel dicho Señor Juez y Cobernador visitando al dicho Juan de Carvajal preso por ante mí el dicho Escribano y testigos yuso escritos dijo al dicho Juan de Carvajal que por cuanto él en las [sic!] declaración que hizo al juramento que le fue tomado de decir verdad conforme a la ley de partida dijo y declaro que nunca fuera en seguimiento de los dichos Felipe de Hutten, Bartolomé Belzar y compañía sino fuera por Sebastián de Almarcha y Pedro de Limpias que para mayor declaración de lo suso dicho y justificación de la causa le mandaba y mandó so cargo del juramento que había hecho digo y declara qué palabras, qué causas y que persuaciones le hicieron y dijeron los dichos Pedro de Limpias y Sebastián de Almarcha para ir y hacer lo que se efectuó e hizo y en tiempos y lugares le dijeron las dichas palabras y per- 
suaciones y si las continuaron hasa [sic!] la ejecución de las muertes que se hicieron; testigos el Teniente Alonso Pérez de Tolosa y Juan de Guevara ${ }^{78}$ ( $M$ : $\left.\mathrm{N}^{\circ} 187,537 f.\right)$.

Wenn wir davon ausgehen, dass dieses officialese integraler Bestandteil des Zeichengebrauchs und somit selbst Bedeutungsträger ist: Wie ist dann diese >Bedeutung< zu umschreiben? Umgekehrt gefragt: Was hat es zu bedeuten, dass im interrogatorio der Gebrauch des officialese deutlich zurückweicht? Die Sprache der Befragung, Carvajals Antworten und die >Erläuterung zu seinem Geständnis (siehe unten) wirkt durch das Zurücktreten der Amtssprache sauthentischer , dem >Urtext $<$ näher als an den meisten anderen Stellen im Prozess, aber auch weniger offiziell. Es scheint, als ob Carvajals Aussage zwar der Form halber aufgenommen, aber nicht in den Fokus der Aufmerksamkeit des Gerichts geraten wäre. Carvajals Ausführungen hätten Anlass sein können für weitere Untersuchungen, die ihn möglicherweise entlastet hätten. Im Urteil des Richters Tolosa, das er fünf Tage später verkündete, finden Carvajals Ansätze zur Verteidigung - Hutten als Aufständischer, der ihn, Carvajal, töten wollte, und die Irreführungen von Pedro de Limpias und Sebastián de Almarcha, denen er vertraut habe - keinen Widerhall. Wenn man Carvajals Erläuterung seines Geständnisses liest, stellt man fest, dass auch diese weitgehend frei ist von juristischen Floskeln; nach den einleitenden Sätzen fallen sie fast ganz weg:

Después de lo suso dicho en once del mes de septiembre del dicho año el dicho Juan de Carvajal declarando sobre ciertas preguntas que le fueron hechas por el dicho que tiene hecho después de haber pasado la rebelión y alzamiento que los dichos Capitán Felipe de Hutten y Bartolomé Belzar y sus consortes cometieron en este campo le dio a este confesante un dolor en el corazón tan grave que naturalmente pensó morir del que no sosegaba de día y de noche y hablando con los dichos Sebastián de Almarcha y Capitán Pedro de Limpias sobre lo sucedido queriendo saber que manera se podría tener para que los dichos delincuentes fuesen castigados le dijo el Capitán Pedro de Limpias que si los queria tomar que los que dejase ir ocho o nueve jornadas adelante y que después fuese en su seguimiento y que los tomaría sin ningún riesgo y al dicho Sebastián de Almarcha le pareció lo mismo, y le dijo y aconsejó que porque la gente de este campo estaba casi toda en favor del dicho Felipe de Hutten que tuviese manera como se apercibiese gente para que saliesen de este campo al Asiento de Quibore y que él y el Capitán Pedro de Limpias saldrían adelante con la dicha gente y después que los tu- 
viesen allá les ganarían las voluntades para que fuesen en seguimiento de los dichos rebelados diciendo que llegados en Coro harían lo mismo que aquí había hecho con el Alcalde Mayor Rodrigo Infante ${ }^{79}$ y que de no remediar un daño semejante se recrecerían otros muchos y así se apercibió la dicha gente y salieron adelante los dichos Capitán Pedro de Limpias y Sebastián de Almarcha y este confesante salió dos o tres días después y los fue a alcanzar al Asiento de Quibori y allí preguntó a los dichos Sebastián de Almarcha y Capitán Pedro de Limpias que voluntad reconocerían de la gente y le dijo el dicho Sebastián de Almarcha que todos perderían sus vidas en servicio de Su Majestad y que por no haber en lo pasado algunos hechos el deber al tiempo de la rebelión y alboroto estaban corridos y que para más los atraer a su voluntad les había dicho que el dicho Capitán Felipe de Hutten había publicado que quería más en su tierra ser porquero de un hato que no Gobernador de tan ruin gente y que le había levantado otros testimonios para indignarlos y así este confesante teniendo por cierto que los dichos Capitán Pedro de Limpias y Sebastián de Almarcha eran verdaderos y leales servidores de Su Majestad y por tales los tuvo porque en el tiempo que sucedió la rebelión y alboroto cuando le quisieron matar no halló otros que con mejor voluntad acompañasen su persona y le guardasen de día y de noche y al tiempo que se publicó que el dicho Capitán Felipe de Hutten tenía acordado de revolver desde Quibori sobre este campo y matar a este confesante y alzarse con la tierra, los dichos Sebastián de Almarcha y Capitán Pedro de Limpias de noche le acompañaban con sus armas y le guardaban y cabalgaban en sus caballos los cuartos del alba, por manera que teniendo por cierto que Su Majestad sería muy servido que los dichos alzados fuesen castigados y que por ello le haría mercedes determinó de salir del dicho Asiento de Quibori en su seguimiento lo cual no hiciera sino fuera por los dichos Capitán Pedro de Limpias y Sebastián de Almarcha y por creer y tener por cierto que en ello servía a Su Majestad y así fueron en su seguimiento y los alcanzaron en las sierras camino de Coro y fueron presos y sucedido lo que tiene dicho en su confesión a que se refiere y que esta es la verdad para el juramento que hizo y firmolo de su nombre. Juan de Carvajal ${ }^{80}\left(\mathrm{M} \mathrm{N}^{0} 187,537-539\right)$.

Umgekehrt ausgedrückt: Die Teile der Akten, die für die Entlastung Carvajals sprechen könnten, tragen am wenigsten Merkmale des officialese. Sie fallen offensichtlich für die endgültige Beurteilung des Falls am wenigsten ins Gewicht. Sowohl sprachlich als auch inhaltlich bleiben Carvajals Aussagen innerhalb der Akten ein Fremdkörper. 
Am 13. September wird das Urteil des Richters Juan Pérez de Tolosa veröffentlicht. Darin kommt er, nach dutzenden Sätzen in ausgeprägtestem officalese, $\mathrm{zu}$ folgendem Schluss:

[E]I dicho Juan Deldua probó bien y cumplidamente su intención y querella con mucho número de testigos y confesión del dicho Juan de Carvajal de más de la notoriedad y evidencia del hecho en haber muerto y degollado por los cogotes alevosamente sin ser oidos ni vencidos sobre treguas y seguro de paz a los dichos Felipe de Hutten y Bartolomé Belzar y Gregorio de Plasencia y Diego Romero ${ }^{81}$ (M: $\left.\mathrm{N}^{0} 188,540\right)$.

Richter Tolosa und seine »ersten Begleiter« verurteilen Juan de Carvajal zum Tod durch den Strang, und

a que sea sacado de la cárcel pública donde está, atado a la cola de un caballo y por la plaza de este Asiento sea llevado arrastrando hasta la picota y horca y allí sea colgado del pescuezo con una soga de esparto, o de cáñamo, de manera que muera muerte natural y ninguno de allí sea osado de le quitar sin licencia de mé el dicho Gobernador so pena de muerte ${ }^{82}\left(M: N^{0} 188,541\right)$.

Zudem muss er die Kosten dafür tragen, dass die Zeugen nach El Tocuyo gebracht werden mussten. Der escribano sorgt gleich auch noch für die Sicherstellung der Entschädigung aller Schreibarbeiten der escribanos (vgl. ebd.).

Angesichts des Todes gesteht Juan de Carvajal am 17. September 1546 seine alleinige Schuld. Die anderen, die er anfangs beschuldigt hatte, hätten nur gemacht, was er ihnen befohlen habe, in der Annahme, damit dem König zu dienen. Wenn er gegen die anderen Gefangenen etwas ausgesagt habe, dann sei dies schlecht und falsch ausgesagt worden, um sein Leben zu retten, und nicht, weil irgendeiner von ihnen in irgendeiner Weise schuldig am Tod der Opfer sei. Und dies sei die Wahrheit (vgl. M: $\mathrm{N}^{\mathrm{o}}$ 189, 543). Unmittelbar nach der Feststellung dieser >Wahrheit` wurde das Urteil vollstreckt und bezeugt:

Y hecha la dicha confesión y declaración susodicha, la dicha sentencia fue acabada de ejecutar en el dicho Juan de Carvajal y fue pedido por testimonio por Juan Deldua (sic!) Alguacil Mayor a quien fue mandada ejecutar, testigos los sobredichos y Juan Ortiz de Zárate y Marcos de Aponte estante en el dicho Asiento. ${ }^{83}$ Juan Quincoces de Llana, Escribano; Licenciado Juan Pérez de Tolosa, Juez y Gobernador ${ }^{84}$ (ebd). 


\section{Verquickung der beiden Prozesse}

Die Verquickungen zwischen den beiden Prozessen zeigen sich, indem man die Chronologie der Ereignisse, die in beiden Akten aufgeführt sind, nebeneinanderlegt (vgl. dazu Tabelle 3 im Anhang, welche die beiden Prozesse in ihren Teilschritten zeigt). Vier Aussagen lassen sich bereits nach einem kurzen Blick auf Tabelle 3 treffen:

Erstens zeigt der obere Teil der Tabelle, dass das erste Dokument der Akte des Kriminalprozesses, $\mathrm{N}^{\circ} 169$, ein Ereignis dokumentiert, das 20 Tage nach dem Startschuss des Kriminalprozesses stattgefunden hat. Damit wird klar, dass der Prozess gegen Carvajal vor der Residencia gegen die Welser in für die Öffentlichkeit wahrnehmbarer Weise begonnen hat. Für die Bewohner Coros mussten sich so die beiden Prozesse als miteinander verbunden darstellen.

Zweitens zeigt die Aufstellung, dass insgesamt drei escribanos an der Erstellung der Akten beteiligt waren, wobei Tolosa Ramos de Argañarás (Schreibung variierend mit Dargañarás) mit der Abschrift der Residencia und Juan Quincoces de Llana mit der Endredaktion des Kriminalprozesses beauftragt hatte.

Drittens bleiben die Felder in der zweiten Spalte, die die Schritte der Residencia zeigen, leer ab dem Moment, in dem der Kriminalprozess gegen Carvajal mit der Klageschrift des Staatsanwalts einsetzt (29. Juni 1546). Das heißt, dass die Residencia zugunsten des Kriminalprozesses ausgesetzt wurde. Dies ist erstaunlich angesichts des recht hohen Einsatzes zu Beginn, als der pregón ausgerufen beziehungsweise in der Kirche ausgehängt wurde und die erste Fragerunde nach >Drehbuch <urchgeführt wurde. Wozu also diese Mühen, wenn die Residencia anschließend im Sande verläuft und alle Kräfte in den Kriminalprozess fließen? Was ist mit der königlichen Ernennung Tolosas zum Juez de Residencia? Konnte er diese ohne weiteres beiseiteschieben? Bot ihm der Kriminalprozess bessere Möglichkeiten zur Profilierung als die Residencia? Es ist zu vermuten, dass die Gerüchte um die Enthauptungen Grund genug waren, die Pläne kurzfristig und bedarfsgerecht zu ändern, zumal Carvajals Tat de oficio, von Amtes wegen, verfolgt wurde. In der Provisión für die Residencia steht ausdrücklich, Tolosa solle sich kundig machen in allen zivil- und strafrechtlichen Fällen, die aufgebracht würden. Auf jeden Fall aber mussten die Akten den Beweis antreten, dass sich besagte Planänderung rechtfertigte. Also galt es, ein dramatisches Bild der Lage in der Provinz zu zeichnen, was dem Untersuchungsrichter Juan Pérez de Tolosa gleichzeitig die Gelegenheit verschaffte, sich selbst als treuen Diener seiner Majestät darzustellen, indem er 
zeigte, dass er für Ordnung sorgte und dem Recht zur Durchsetzung verhalf. Das Mittel, dessen er sich dabei bediente, war das Schreiben.

Viertens wird ersichtlich, dass der Kriminalprozess die Akten nicht chronologisch ordnet, sondern mit der eben erwähnten Klageschrift vom 30. Juni 1546 einsetzt. Gemäß Cornelia Vismann verfügen Akten über keine feste Form (vgl. Vismann 2011: 7); anders als Bücher seien sie lose gebunden, könnten ergänzt und umgeschichtet werden. Die Reihenfolge, in der die Aktenteile zu einem Ganzen zusammengefügt werden, unterliegt somit der Gewichtung der Person, die das Anlegen der Akte anordnet. Was harmlos klingt, kann für die Bedeutung des Textes und die Lektüre erhebliche Konsequenzen nach sich ziehen, wie das Beispiel der Akten des Kriminalprozesses gegen Carvajal zeigt. Die Anordnung der Teilakten entsprechen nicht der chronologischen Abfolge der Prozessschritte; beginnt der Leser oder die Leserin die Lektüre mit dem ersten Dokument, das die Klageschrift des Vertreters der Anklage enthält (Zeile 12 von Tabelle 3, Dokument $\mathrm{N}^{\mathrm{o}} 169$ ), wird unter Umständen nicht klar, dass Tolosa bereits 20 Tage zuvor seine öffentliche Vorverurteilung Carvajals als heimtückischen Mörder kundgetan hatte. Mit der Umstellung der Reihenfolge könnte die Tatsache verdunkelt worden sein, dass alle Zeugenaussagen nach Tolosas Rede vom 10. Juni 1546 aufgezeichnet wurden und sie durch die Rede beeinflusst worden waren, zumal die Vorverurteilung vom Juez de Residencia stammte, dem in jenem Moment höchsten Würdenträger in der Hierarchie der lokalen Administration. Für diese These spricht die Tatsache, dass alle Zeugenaussagen in der Schuldfrage übereinstimmen.

Der Umstand, dass Tolosa seine Vorverurteilung nur aufgrund erster Berichte und schon vor der Aufnahme der Zeugenaussagen und Anhörung des Beschuldigten gefällt zu haben scheint, wirft grundsätzliche Fragen auf. Welche Ziele verfolgte Tolosa mit der Durchführung des Kriminalprozesses? Ging es tatsächlich darum, die >Wahrheit< hinter den Vorwürfen gegen Carvajal herauszufinden? Hätte Tolosa seine Verurteilung Carvajals überhaupt noch revidieren können, wenn die Untersuchung die Unschuld Carvajals nachgewiesen hätte? Muss man den Prozess im Lichte der »Belohnungsökonomie« (Brendecke 2009a: 54) oder »economy of mercedes « (Folger 2011: 5f.) sehen, in dem Sinne, dass Tolosa durch die Darstellung seiner Dienste für den König, die ihm der Prozess ermöglichte, eine Vergütung erwirken wollte? Für diese These spricht zumindest die Tatsache, dass Tolosa in seinem Brief an den König die Verhaftung Carvajals berichtet und im Anschluss daran um eine Entlohnung ersucht. Oder ging es (auch) darum, Einigkeit unter den Bewohnern der Provinz (wieder) herzustellen? Da der Kriminalprozess im Grunde 
aus dem Juicio de Residencia hervorging, wäre dies durchaus denkbar: So wie Tamar Herzog die Funktion der Residencias als "Kommunikationsinstanzen« (2004: 164) beschreibt, durch deren Zeremoniell die Verwaltung, die Rechtssprechung, die Gemeinschaft und der soziale Friede wieder hervorgebracht worden seien, könnte auch der Prozess gegen Carvajal in ähnlicher Weise gewirkt haben, zumindest auf lokaler Ebene.

\section{Gerichtsuntersuchung und ,Wahrheitssucher}

Wie das Protokoll der Befragung Carvajals zeigt, führt sie aus mehreren Gründen nicht zur Erkenntnis einer hieb- und stichfesten >Wahrheit< im Sinne einer modernen Kriminal- und Justizpraxis. Einerseits ist der Zugang zur Erinnerung Carvajals verstellt, aus welchen Gründen auch immer. Andererseits werden belastende Aussagen zu Almarcha und Limpias fallengelassen, und die Schuld wird ausschließlich auf Juan de Carvajal fokussiert. Hier stellt sich die Frage nach dem Warum: Warum findet keine >Wahrheitssuche im modernen kriminologischen Sinne statt? Denn immerhin ortet Foucault - so Siegert - die »Genese der empirischen Wissenschaften « (Siegert 2003a: 539) in genau solchen gerichtlichen Untersuchungen. Er führt sie - wie Siegert schreibt - auf die »abstrakte Formek der inquisitio (enquête) zurück« (ebd.). Siegert zitiert Foucault weiter:

Tatsächlich war die Cerichtsuntersuchung der erste aber grundlegende Ansatz zur Konstituierung der empirischen Wissenschaften; sie war die juristisch-politische Matrix des experimentellen Wissens, das am Ende des Mittelalters plötzlich entriegelt worden ist. Die Mathematik mag in Griechenland aus den Techniken des Messens entstanden sein; die Wissenschaften von der Natur sind jedenfalls zum Teil am Ende des Mittelalters aus den Techniken der Cerichtsuntersuchung hervorgegangen. Das große empirische Erkennen, das die Dinge der Welt überzogen hat und in die Ordnung eines unbegrenzten, die »Tatsachen « feststellenden, beschreibenden und sichernden Diskurses transkribiert hat (und das in dem Augenblick, in dem die abendländische Welt mit der ökonomischen und politischen Eroberung eben dieser Welt begann), dieses empirische Erkennen hat zweifellos sein Operationsmodell in der Inquistion - jener unermeßlichen Erfindung, die unsere moderne Verzärtelung in einer schattigen Ecke unseres Cedächtnisses abgestellt hat. (Foucault ${ }^{85}: 289 f$., zitiert nach Siegert 2003a:540) 
Als Urszene der Wissenschaften beschreibe Foucault die Szene in Sophokles' Oidipus tyrannus, in der Ödipus den alten Schafhirten befragt, der bezeugt, dass er Ödipus als kleines Kind einem Diener des Königs Polibos übergeben hatte. Gleichzeitig war er Zeuge des Mordes, den Ödipus Jahre zuvor an seinem Vater begangen hatte, und darüber sollte er jetzt im Palast des Ödipus Auskunft geben. Als nun derselbe Diener des Polibos die Botschaft von dessen Tod Ödipus überbringt, erkennen sich der Bote und der alte Schafhirte wieder, und die ganze Wahrheit kommt ans Licht: Ödipus ist der Mörder seines Vaters! Es handelt sich um eine Befragung,

in der zum ersten Mal der für die abendländische Auffassung der Wahrheit fundamentale gegenseitige Ausschluß von Macht und Wissen zum Vorschein kommt. Hier der ohnmächtige Hirte, der weiß und dessen Rede nichts weiter sagt als sich erinnere mich, ich habe gesehen<, dort der mächtige König, der allen mit dem Tode droht, der aber nicht weiß. (Ebd.: 541)

Als Augenzeuge könne der Hirte eine »Wahrheit ohne Macht einer Macht ohne Wahrheit « gegenüberstellen, was die »Entwicklung eines Erkenntnistyps, der auf Zeugenschaft, auf Erinnerung beruht«, zeige (ebd.). Auch Carvajal sagt: »[I]ch erinnere mich/ich habe gesehen««, aber heißt das, dass er >Ohnmächtiger < ist, der weiß, während Tolosa den >Mächtigen` darstellt, der mit dem Tode droht und nicht weiß? Zur Beantwortung der Frage muss gesagt werden, dass Carvajal nicht einfacher Augenzeuge ist, der gewissermaßen nur als Instrument der Wahrnehmung dient. Auch er manipuliert die Macht, indem er in den entscheidenden Augenblicken der Befragung seinen Dienst als Augenzeuge verweigert und sich hinter der Äußerung: »Ich erinnere mich nicht«, versteckt.

Obige Frage ist also falsch gestellt. Wie wir gesehen haben, kommt der Text der Akten gerade durch die starke Verflechtung zwischen Macht und Wissen und nicht durch deren Trennung zustande. Die Interpellation ist durch die Wirkung des bürokratischen Apparats in vollem Gange, entzündet durch die Rede Tolosas in öffentlicher Versammlung vom 10. Juni. Auch das Handeln aller Beteiligten während der blutigen Auseinandersetzungen zwischen Hutten und Carvajal muss vor dem Hintergrund der Macht beziehungsweise deren Legitimation gesehen werden. So hätte die Enthauptung Huttens und seiner Gefolgsleute durch Carvajal durchaus gerechtfertigt erscheinen können, wäre seine Macht als Gouverneur und Generalkapitän unangefochten gewesen.

Der auf diese Weise gestaltete Wahrheitsbegriff passt auch gut zu den Ergebnissen der vorliegenden Studie. Insbesondere die beschriebene textuelle 
Konstituierung des (kolonialen) Subjekts beziehungsweise Subjektgefüges und mit diesen einer (kolonialen) >Wahrheit< - könnte einen der möglichen Wege der diskursiven Konstituierung eines >Erkenntnissubjekts aufzeigen, nach denen Foucault (vgl. 2002) in dem Beitrag »Die Wahrheit und die juristischen Formen« fragt. Erkenntnis oder >Wahrheit` hält gemäß der These nicht über das Subjekt »Einzug in die Geschichte«, sondern »über einen Diskurs im Sinne eines Ensembles von Strategien« (ebd.). Diese Strategien seien »Teil der sozialen Praktiken« (ebd.). Dabei zählt Foucault die juristischen zu den wichtigsten »sozialen Praktiken, deren historische Analyse die Entstehung neuer Formen des Subjekts zu lokalisieren erlaubt « (ebd.: 672). Die im Prozess gegen Carvajal gezeigte prekäre Wahrheitsfindung entspricht in diesem Sinne genau Foucaults These, gemäß der >Wahrheit nicht außertextuell und der Textproduktion vorgelagert $\mathrm{zu}$ fassen ist, sondern erst mit der Produktion des Archivs geschaffen wird.

Dass Carvajal in seinen Aussagen vor Gericht eine Art Gegendiskurs entfesselt, nützt ihm für sein Überleben wenig. Als ehemaliger Notar ist er zwar in die Gesetze, Mechanismen und sprachlichen Codes des bürokratischen Apparats eingeweiht. Dies nützt ihm jedoch wenig, denn ohne Anschluss an die >Nabelschnur<, zur Legitimation der Macht, fehlt dem Diskurs des in Ungnade Gefallenen jede Wirkungskraft. Er wird zwar transkribiert, verhallt jedoch in den Weiten des Archivs der Kolonialgeschichte.

Ziel der Prozesse war nicht kriminologische >Wahrheitsfindung $<$, sondern in erster Linie (Wieder-)Herstellung der/einer Ordnung. Schmitt schreibt zum Prozess gegen Carvajal: "Ein Nebeneffekt des Verfahrens war, daß nach den Spannungen, Unruhen und Rechtsbeugungen der Zeit der WelserStatthalterschaft und der Ära Carvajal jedermann in der Provinz klar wurde, was unter königlicher Autorität eigentlich zu verstehen sei« (1999: 129). Dem ist nur beizupflichten - ob der Effekt allerdings bloß als »Nebeneffekt« zu bestimmen ist, lässt sich nach den Ausführungen in diesem Kapitel bestreiten. Der Verlauf und das Ergebnis des Prozesses sprechen eine andere Sprache: Die Akten der beiden Prozesse und deren Leerstellen - die Nichtfortführung des Juicio de Residencia zu den Welsern - sind Zeugen und Produkt der Erzeugung und Etablierung eines kolonialen >Alltags $<$. Dazu gehören auch die Anerkennung und die Unterordnung unter den Souverän. 